\title{
The Impact of COVID-19 on Small Business Outcomes and Expectations
}

Alexander Bartik

Marianne Bertrand

Zoë B. Cullen

Edward L. Glaeser

Michael Luca

Christopher Stanton

Working Paper 20-102 


\section{The Impact of COVID-19 on Small Business Outcomes and Expectations}

\author{
Alexander Bartik \\ University of Illinois \\ Marianne Bertrand \\ University of Chicago \\ Zoë B. Cullen \\ Harvard Business School
}

\author{
Edward L. Glaeser \\ Harvard University \\ Michael Luca \\ Harvard Business School \\ Christopher Stanton \\ Harvard Business School
}

Working Paper 20-102

Copyright (c) 2020 by Alexander Bartik, Marianne Bertrand, Zoë B. Cullen, Edward L. Glaeser, Michael Luca, and Christopher Stanton.

Working papers are in draft form. This working paper is distributed for purposes of comment and discussion only. It may not be reproduced without permission of the copyright holder. Copies of working papers are available from the author.

Funding for this research was provided in part by Harvard Business School. 


\title{
The impact of COVID-19 on small business outcomes and expectations*
}

\author{
Alexander W. Bartik, Marianne Bertrand, Zoe Cullen, Edward L. Glaeser, Michael Luca, and \\ Christopher Stanton
}

\begin{abstract}
To explore the impact of COVID on small businesses, we conducted a survey of more than 5,800 small businesses between March 28 and April 4, 2020. Several themes emerged. First, mass layoffs and closures had already occurred - just a few weeks into the crisis. Second, the risk of closure was negatively associated with the expected length of the crisis. Moreover, businesses had widely varying beliefs about the likely duration of COVID-related disruptions. Third, many small businesses are financially fragile: the median business with more than $\$ 10,000$ in monthly expenses had only about two weeks of cash on hand at the time of the survey. Fourth, the majority of businesses planned to seek funding through the CARES act. However, many anticipated problems with accessing the program, such as bureaucratic hassles and difficulties establishing eligibility. Using experimental variation, we also assess take-up rates and business resilience effects for loans relative to grants-based programs.
\end{abstract}

\footnotetext{
* We thank Karen Mills for connecting us to the leaders at Alignable and to Eric Groves, Venkat Krishnamurthy, and Geoff Cramer for immense help in facilitating survey distribution. Dylan Balla-Elliott, Manal Saleh, and Pratyush Tiwari provided excellent research assistance. Author contact information is: Alexander Bartik is at the University of Illinois: abartik@illinois.edu, Marianne Bertrand is at the University of Chicago Booth School of Business: Marianne.Bertrand@chicagobooth.edu, Zoe Cullen is at Harvard Business School: zcullen@hbs.edu, Ed Glaeser is at the Harvard Department of Economics: eglaeser@harvard.edu, Michael Luca is at Harvard Business School: mluca@hbs.edu, and Christopher Stanton is at Harvard Business School: cstanton@hbs.edu.
} 


\section{Introduction}

In addition to its impact on public health, COVID-19 has caused a major economic shock. In this paper, we explore the impact of COVID-19 on the small business landscape in the United States, focusing on three questions. First, how did small businesses adjust to the economic disruptions resulting from COVID-19? Second, how long did businesses expect the crisis to last, and how do expectations affect their decisions? Third, how might alternative policy proposals impact business and employment resilience?

To explore, we surveyed more than 5,800 small businesses that are members of Alignable, a network of 4.6 million small businesses. The survey was conducted between March 28 and April 4, 2020. The timing of the survey allows us to understand expectations of business owners at a critical point in time when both the progression of COVID-19 and the government's response were quite uncertain.

The results suggest that the pandemic had already caused massive dislocation among small businesses just several weeks after its onset and prior to the availability of government aid through the CARES Act. Across the full sample, 43 percent of businesses had temporarily closed and nearly all of these closures were due to COVID-19. Respondents that had temporarily closed largely pointed to reductions in demand and employee health concerns as the reasons for closure, with disruptions in the supply chain being less of a factor. On average, the businesses reported having reduced their active employment by 39 percent since January. The decline was particularly sharp in the Mid-Atlantic region (which includes New York City), where 54 percent of firms were closed and employment was down by 47 percent. Impacts also varied across industries, with retail, arts and entertainment, personal services, food services, and hospitality businesses all reporting employment declines exceeding 50 percent; in contrast, finance, professional services, and real estate related businesses experienced less disruption, as these industries were better able to move to remote production.

Our results also highlight the financial fragility of many small businesses. The median firm with expenses over $\$ 10,000$ per month had only enough cash on hand to last approximately two weeks. Three-quarters of respondents reported that they only had enough cash on hand to 
cover two months of expenses or less ${ }^{\dagger}$. Not surprisingly, firms with more cash on hand were more optimistic that they would remain open by the end of the year.

Our survey also elicited businesses' beliefs about the evolution of the crisis, allowing us to study the role of beliefs and expectations on decisions. The median business owner expected the dislocation to last well into mid-summer, as $50 \%$ of respondents believed that the crisis would last at least until the middle of June. However, beliefs about the likely duration of the crisis varied widely. This raises the possibility that some firms were making mistakes in their forecasts of how long the crisis will last. ${ }^{\ddagger}$

The crisis duration plays a central role in the total potential impact. For a crisis lasting 4 months instead of 1 month, only 47\% of businesses expected to be open in December compared to $72 \%$ under the shorter duration. There is also considerable heterogeneity in how sensitive businesses are to the crisis. In-person industries like personal services or retail reported much lower prospects for riding out the pandemic than professional services or other sectors with minimal need for face-to-face contact.

Lastly, our analysis explores variants of stimulus packages that were being discussed at the time of the survey. The results show that over $70 \%$ of respondents anticipated taking advantage of aid when asked about a program that resembles the Paycheck Protection Program (PPP) that is part of the CARES act. Moreover, they expected this funding to influence other business decisions - including layoff decisions and staying in business altogether. At the same time, many businesses were reluctant to apply for funding through the CARES Act because of concerns about administrative complexity and eligibility. A large number of respondents also anticipated problems with accessing the aid, citing potential issues such as bureaucratic hassles and difficulties establishing eligibility.

Our survey was constructed to allow for a counterfactual evaluation of a straight loan policy, which is a stylized representation of traditional SBA disaster relief programs. While the more generous PPP program does improve take-up and business outcomes, traditional loans with speedy delivery and sufficient liquidity are also found to meaningfully shift business owners' expectations about survival. When compared to a straight loan without forgiveness provisions,

\footnotetext{
${ }^{+}$See Faulkender (2002), La Rocca et al (2019) for discussions of cash holdings of small businesses.

₹ See Goldfarb and Xiao (2011), DellaVigna and Gentzkow (2019), Strulov-Shain (2019) for a related literature on the behavioral economics of firm decisions.
} 
the CARES act had modestly greater take-up, but at much higher cost to the government. Because the majority of business owners would have taken up aid in the form of less generous loans, our results suggest that liquidity provision was paramount for these owners.

Overall, our paper contributes to our understanding of the economic impact of COVID19 on the small business ecosystem. The fate of the $48 \%$ of American workers who work in small businesses is closely tied to the resilience of the small business ecosystem to the massive economic disruption caused by the pandemic. Our survey, which was conducted during a period of substantial policy uncertainty and before any federal response had been enacted, provides a unique snapshot into business decisions and expectations at that time, while offering insight for policy designed to aid the recovery. Our results help quantify how the length of the crisis will determine its ultimate impact, which policy makers should consider as they contemplate the scale of the required interventions. We estimate that closures alone might lead to 32.7 million job losses if the crisis lasts for four months and 35.1 million job losses if the crisis lasts for six months. While some of these workers will surely find new jobs, these projections suggest that the scale of job dislocation could be larger than anything America has experienced since the Great Depression and larger than the impact of the 1918 influenza epidemic found by Barro, Ursua and Weng (2020) and Garrett $(2007,2008)$. Another important take-away of our work is that during liquidity crunches with significant cash flow disruptions, the form of cash injection (e.g. grant vs. loan) may be less important than making sure that funding is rapidly available with little administrative complexity. $§$

The rest of the paper proceeds as follows. Section 2 discusses the survey design. Section 3 discusses the characteristics of the firms that responded to the survey and their representativeness. In Section 4, we explore the current and expected impacts of COVID-19 on these businesses. In Section 5, we present results from a module of the survey that experimentally varies policy proposals, allowing us to explore responses to policies such as the recently passed CARES Act as well as alternative policies. Section 6 considers survival rate differences across industries, and how survival depends on the duration of the crisis. We conclude in Section 7.

\footnotetext{
$\S$ This echoes a growing literature that suggests that reducing simplifying or providing assistance in the process of signing up for programs can increase take-up. For examples, see Bettinger et al (2012) and Finkelstein and Notowidigdo (2019).
} 


\section{Survey Design and Details}

Our survey was sent out in partnership with Alignable, a network-based platform focused on the small business ecosystem. Alignable enables businesses to share knowledge and interact with one another, and currently has a network of 4.6 million small businesses across North America. Much of the network growth has been organic, with little outside marketing.

Alignable also regularly sends out polls (which they call "pulse surveys") to users. At the end of a regular pulse poll, participants who took that poll received an email inviting them to participate in a more comprehensive survey being conducted by researchers at Harvard Business School. Appendix 1 shows the message seen by respondents who opted to participate in the additional survey. Participants were shown a disclosure statement and consent protocol. No payments were offered; participation was completely voluntary.

We received 7,511 responses between March 27 and April 4. 5,843 of these can be traced back to U.S. based businesses, which is the relevant sample for understanding policy. While the 7,511 responses represent a small fraction (.017 percent) of Alignable's total membership, it represents a much larger share of Alignable's membership that has engaged with their weekly pulse surveys on COVID-19. Alignable estimates that 50,000-70,000 members are taking these pulse surveys weekly, which suggests a 10 - 15 percent conversion rate of these more active respondents.

Our sample, therefore, is selected in three ways: (1) they are firms that have chosen to join Alignable, (2) they are Alignable firms that have chosen to stay actively engaged taking surveys, and (3) they are the set of firms that are active within Alignable that chose to answer our survey. Consequently, there are many reasons to be cautious when extrapolating to the entire universe of America's small businesses. We will discuss their representativeness based on observable attributes in the next section of this report.

The survey included a total of 43 questions, with basic information about firm characteristics (including firm-size and industry), questions about the current response to the COVID-19 crisis, and beliefs about the future course of the crisis. Some questions were only displayed based on skip logic, so most participants responded to fewer questions. The survey also includes an experimental module that randomized scenarios between respondents to understand how different federal policies might impact these firms' behavior and survival as the crisis unfolds. Specifically, we experimentally varied some of the descriptions of potential 
policies across the sample to shed light on the potential impact of policy initiatives that, at the time, were very uncertain. We will discuss that module more thoroughly in Section V. A further experimental module included between-respondent randomization which explored decisions under different hypothetical durations of the crisis.

\section{Firm Characteristics and Representativeness}

The survey contains three baseline questions which enable us to assess the representativeness of the sample along observable dimensions: number of employees, typical expenses (as of January 31,2020), and share of expenses that go towards payroll. We are also able to get rough information about geolocation to assess representativeness by state.

We compare our data with data on businesses from the 2017 Census of US Businesses, using the publicly available statistics published by the US Census Bureau. The underlying data is drawn from the County Business Patterns sampling frame and covers establishments with paid employees, including sole-proprietorships if the owner receives a W2. The Census data captures large and small businesses alike, but for our comparisons, we will look only at businesses with fewer than 500 employees.

The Alignable network allows users to share customer leads, which could potentially skew our sample towards retail and service businesses that interact directly with consumers. Since retail businesses are particularly vulnerable to COVID-19 disruptions, our sample could overstate the aggregate dislocation created by the crisis. Naturally, industries dominated by large firms, such as manufacturing, are under-represented. However, as we discuss later, our data on the industry mix of responses suggests that the sample represents a wide swath of America's smaller businesses.

Figure 1 shows the size distribution of our sample and the size distribution of businesses with fewer than 500 employees in the Economic Census. The match of employment sizes is reassuring. About 64 percent of the businesses in our sample have fewer than five employees, while about 60 percent of the firms in the Economic Census are that small. About 18 percent of businesses in both samples have between 5 and 9 employees. The survey becomes less precisely matched to the Census among the larger employment groupings, and we believe that our survey will capture the experience of larger employers with less accuracy. 
While our survey does not allow for an apples-to-apples comparison of payroll expenses with Census data, we constructed a rough comparison by approximating payroll expenses for the Alignable firms from categorical questions about monthly expenses and the share of these expenses going toward payroll. The Census provides annual payroll expenses for W2 employees. To get a sense of the match, we compared our estimated monthly payroll expenses in our sample with one-twelfth of annual expenses in the U.S. Census. To facilitate comparison, we divide by an estimate of total employment. ${ }^{* *}$ Figure 2 shows the size distribution of monthly estimated payroll expenses in our sample and a comparable breakdown for the Census using a per-capita adjustment. The match is imperfect, especially for larger firms. The discrepancy might reflect the under-representation of manufacturing or professional services firms in our sample, which are among the highest paying of all 2-digit NAICS sectors in the Census data. Appendix Table 1 provides further detail on the industry match to the Census.

Figure 3 shows the geographic scope of our sample. The Alignable sample draws particularly from California, the New York region, Florida, and Texas. The sample is sparse in America's western heartland, which matches the location distribution of smaller businesses in the Economic Census.

Figure 4 shows the share of our sample coming from the 10 most populous states. The figure also includes the share of small businesses in the Economic Census that are within each state. For example, California has 14.4 percent of our Alignable survey sample, 12.5 percent of small businesses in the Census data and 11.52 percent of total U.S. population. Our sample does overrepresent the coasts and underrepresents Illinois. Alignable shared the geographic distribution of their weekly pulse survey takers and the final set of columns within each grouping allows us to assess selection differences between respondents to the shorter pulse poll and our downstream survey. There are some minor sampling differences across states, but the Alignable pulse poll sample and those taking our broader survey have quite good geographic coverage.

\footnotetext{
** This comparison is very likely to include different "headcount" as we do not disambiguate between W2 and 1099 employment in the survey whereas the Census data only includes W2 employment who are more likely to be fullyear, full-time employees. Although we cannot disambiguate part-time W2 employees who would show up in the Census versus contractors who would not, $32 \%$ of the January employment captured in the survey falls into the category. According to Current Population Survey data for 2019, about $17 \%$ of the broader labor force was parttime; recent figures on the number of contract workers suggests they made up about $12 \%$ of the labor force in 2016, but they would not have been captured in the Census (Collins et al 2019).
} 
To shed further light on our sample, we conducted a follow up phone screen of 400 businesses - a randomly selected set of 200 businesses that responded to our survey, and 200 businesses from the broader active Alignable membership (i.e. that fill out their previous pulse poll), but who did not respond to our survey. During the phone screen, we asked each business whether they were still open for business. For businesses that did not answer the phone on a first attempt, we made a second attempt to call. Out of the businesses who responded to our survey, roughly $42 \%$ reported being open when we called them. Out of the businesses that are active on Alignable but did not respond to our survey, roughly 56\% reported being open.

Overall, while the sample captured by the survey may be an imperfect snapshot for certain pockets of America's small businesses, it also allows for important insight into the overall small business ecosystem. The sample is large and includes firms from most major industry groups, states, and firm-size categories.

\section{Responses to the COVID-19 Pandemic and Lockdown}

We now turn to our main results, which we group into three categories. First, we describe the impact of COVID-19 on business operations and employment toward the beginning of the crisis. Second, we report our results on the financial fragility of those businesses, as captured by their cash on hand and ongoing expenses. Third, we turn to their expectations about the duration of the crisis and their own economic survival, as measured at a particularly sensitive point for understanding the impact of future policies.

\section{Temporary Closings and Employment}

The initial survey question asked owners "is this business currently operational?" We allowed owners to respond that the business was operational, temporarily closed, or permanently closed. We also allowed them to report whether the business was closed because of COVID-19 or another reason. ${ }^{\dagger \dagger}$

\footnotetext{
${ }^{++}$We did not attempt to assess the quality of firm management, as in Bloom et al. (2013). We hope that future surveys will test when quality of management helps protect firms against closure during this crisis. This crisis also presents an opportunity to understanding managerial decision-making under stress, as discussed by Bazerman and Moore (1994).
} 
Across the sample, 41.3 percent of businesses reported that they were temporarily closed because of COVID-19. A far smaller number - 1.8 percent - reported that they were permanently closed because of the pandemic. By contrast, only 1.3 percent reported that they were temporarily closed for other reasons. 55.5 percent reported that they were still operational.

We also asked the business owners to fill in a matrix that contained the number of fulltime and part-time employees that were employed by the firm "now", as-of the survey date, and on January 31, 2020. Over the entire sample, the number of full-time employees had fallen by 32 percent between January 31 and late-March, 2020. The number of part-time employees was 57 percent lower than at the end of January. Overall employment declined significantly, totaling a 39 percent reduction from January headcount. These results include businesses that had temporarily closed. If we look only at businesses that were still operating, we find that the number of total fulltime employees had fallen by 17.3 percent. The number of part-time employees declined by 34 percent. These estimates can also be compared to other emerging data points. The Atlanta Fed conducted a similar survey (Altig et al 2020), drawn from Dun \& Bradstreet listings, and found smaller employment effects (roughly 10\% decrease in employment). Whereas their survey includes larger firms as well, our focus is on smaller businesses. Further, their survey undersamples newer firms, which may have larger employment changes. We can also compare our results to publicly released aggregated payroll data from ADP (which may have different issues of representativeness). In those data, paid employment at firms with less than 500 employees declined by about 18 percent between January and April ${ }^{\dagger+}$. These data, however, treat anyone receiving pay in April as employed even if they were laid off during or before the interval. Looking at higher-frequency data on paychecks in the ADP microdata, concurrent but independent work by Cajner et al (2020) find that employment declined on average 27 percent for firms with less than 500 employees and about 28 percent for firms with less than 50 employees between mid-February and mid-April. ${ }^{\S}$ These numbers are somewhat

\footnotetext{
H https://adpemploymentreport.com/2020/April/SBR/SBR-April-2020.aspx, accessed on May 21, 2020. We aggregate the estimates across firm size bins to estimate job-losses for firms with 1-499 employees using firm weights. The corresponding estimates using employment weights are also 18 percent. The weights come from the Bureau of Labor Statistics' Business Employment Dynamics figures of the distribution of private sector employment (Table F) and firm size (Table G) for the first-quarter of 2019 (not seasonally adjusted). Data were accessed from https://www.bls.gov/bdm/bdmfirmsize.htm

on May $22^{\text {nd }}$.

$\S \S$ These figures were computed using the estimates in Figure 10 the May 6, 2020 version of the Cajner, et al (2020) paper. We aggregate the estimates across firm size bins to estimate job-losses for firms with 1-499
} 
smaller than the 39 percent decline in employment for small businesses that we find but higher than the estimates of the Atlanta Fed survey.

We then expand to look at geographic variation of the effects. Table 1 shows our results across the eleven Census Divisions and displays the share of businesses that had temporarily closed because of COVID-19 and the reduction in total employment between January 31 and the survey date. The results are not meaningfully different if we separate out full time or part time employees. While there is regional heterogeneity, the disruptions are severe almost everywhere.

The Mid-Atlantic division had the sharpest decreases in employment and the largest share of firms that had temporarily suspended operations. Fifty-four percent of firms in that region were closed in late-March/early-April, and employment had fallen by an average of 47 percent. The Mountain region was the least affected, but even there 39 percent of firms had temporarily closed and employment had declined by 32 percent.

Tables 2 and 3 display the same breakdown by firm size and industry. Smaller firms with fewer than 20 employees in January were more likely to be closed. Firms with between 6 and 19 January employees had the largest employment reductions. Across industries, in-person retail and service businesses had declined precipitously. Although hard hit, the impact was not as extreme for professional services firms - banking and finance, real estate, or construction. Table 3 also allows a comparison of how our results might change if we reweight to the region and firm size cells in the Census data and then cut by industry (a dimension that is not targeted in the reweighting). The results change little across industries in the reweighted data compared to the raw data.

Table 4 shows the problems that firms reported facing, split by their operational status at the time of the survey. We asked owners to rate, on a 1 to 100 scale, the problems they were experiencing with employee illness, supply chains, and customer demand. The scale had both numerical values, and also a text label that went from "Not a concern" at one end to "Extremely disruptive" at the other end. We differentiate between firms that are open, temporarily closed

employees and 1- using firm weights. The corresponding estimates using employment weights are 23 percent job losses for firms with 1-499 employees and 27 percent job losses for firms with 1-49 employees. The weights come from the Bureau of Labor Statistics' Business Employment Dynamics figures of the distribution of private sector employment (Table F) and firm size (Table G) for the first-quarter of 2019 (not seasonally adjusted). Data were accessed from https://www.bls.gov/bdm/bdmfirmsize.htm on May $22^{\text {nd }}$. 
and permanently closed, and we show the share of firms in each category that indicate significant difficulties in each of these areas.

On average, firms rated the disruptions resulting from supply chain challenges to be 35 on the 100-point scale (which is in the "slightly disruptive" part of the scale). Concerns about employee health were more prominent, with firms rating it as 57 out of 100 (which maps to "somewhat disruptive"). Reductions in demand were even more disruptive, with firms rating the importance of this to be 79 out of 100 (extremely disruptive). While closed firms noted worse disruptions due to demand, the basic ranking of the different disruptions was consistent across different types of firms. These findings suggest, thus far, that supply chain problems have been less pronounced, relative to disruptions resulting from demand shocks and concerns about employee health.

Altogether, these results suggest that a vast number of enterprises had temporarily shut down and laid off workers over the first several weeks of the crisis. The impact on business disruptions in the coming months will depend both on the length of the crisis and on the financially fragility of firms. The central role of the demand shock highlights the challenges in adjusting to the financial shock caused by COVID-19 related disruptions. We now directly explore financial fragility, and the extent to which firms' resources might allow them to weather the crisis.

\section{Financial Fragility}

To measure financial fragility, we asked the respondents "roughly how much cash (e.g. in savings, checking) do you have access to without seeking further loans or money from family or friends to pay for your business?" We then divided this amount by their January 31 st monthly expenses to understand how long they could maintain operations without seeking extra credit or outside assistance. $^{* * *}$

Figure 5 shows a histogram of cash available as a multiple of January 31, 2020 monthly expenses. Approximately one-fourth of firms had cash on hand totaling less than one month of

\footnotetext{
${ }^{* * *}$ We did not collect information about access to lines of credit or outside borrowing, but given the severity of the contraction in demand those credit facilities may be unlikely to remain accessible without a government guarantee.
} 
expenses. About one-half of firms had enough cash on hand to cover between one and two months of expenses.

Figure 6 sorts firms by January 31, 2020 monthly expenses and then tabulates the mean and median cash on hand relative to pre-crisis expenses. The median firm with under $\$ 10,000$ in monthly expenses had one month of cash on hand. For all firms with greater than $\$ 10,000$ in monthly expenses, the median firm typically had less than 15 days of cash on hand, based on their pre-crisis expense levels. These firms did not have cash on hand to meet their regular expenses.

These limited levels of cash on hand help to shed light on why layoffs and shutdowns were so prevalent. Absent these actions, it is hard to understand how these firms could have met payroll.

\section{Predicting the Path of the Crisis}

Finally, we ask the firms to predict how long the COVID-19 crisis will last and whether they believe they will be open again at the end of 2020. To predict the end of the crisis, we asked the survey respondents "the most likely date" when the crisis would be over. We also asked them their confidence about this belief on a 1 to 10 scale.

Figure 7 shows the distribution of expected end dates. The figure shows that roughly 20 percent of respondents believed that the crisis would be over by the end of May. 30 percent of

respondents believed that the crisis would end between the end of May and the start of July. Just over one half of the firms answered that they thought that the crisis would still be going at the start of July.

However, the firms were not particularly confident about their answers. 50 percent of respondents reported their confidence level as five or less on the 1 to 10 scale. 16 percent gave their confidence a two or less. Their uncertainty highlights the broader uncertainty that was present throughout the world at the time.

Figure 8 shows the histogram of responses about whether firms will be open on December 31, 2020. Overall, more than 90 percent thought it is at least somewhat likely that they would be open. More than 63 percent reported that it is very or extremely likely that they would be open - which we later use as a measure of the probability of being open. A growing literature has found entrepreneurs to be overoptimistic about their prospects (see, for example, Bazerman 
and Moore 1994). This suggests that true survival rates may be even lower than predicted by businesses.

The firms with more cash on hand were more confident about their future, as evidenced by the split based on whether the firm had more or less cash on hand (relative to usual monthly expenses) than the median in our sample. Fifty percent of those firms with more than the median cash on hand thought it was extremely likely that they would be open at the end of the year. Thirty-one percent of firms with less cash on hand, relative to the median, thought that they would be open at the end of the year. One interpretation of these findings is that liquidity generated confidence in the ability to survive this crisis. Among firms with at least 20 employees, 71 percent expressed that they were either very likely or extremely likely to survive, which may indicate greater access to outside resources despite having a higher expense base.

Figure 9 shows that the share of firms that think that they are "very likely" or "extremely likely" to be open varies based on their belief about the duration of the crisis. The firms that thought that the crisis will be short also believed that they are more likely to survive. Those who believed in a longer crisis were more pessimistic.

\section{Anticipated Responses to CARES Act Programs}

In this section, we discuss the survey's questions about take-up of the CARES Act Paycheck Protection Program (PPP) loans and their expected impact on employment. One important aspect of the CARES program is that "loans will be fully forgiven when used for payroll costs, interest on mortgages, rent, and utilities," as long as 75 percent of the forgiven amount is spent on payroll and the employer either maintains or quickly rehires workers and maintains salary levels (https:/home.treasury.gov/system/files/136/PPP\%20--

\%200verview.pdf). Consequently, a significant portion of the "loans" can be seen as a grant rather than traditional debt.

The high level of loan forgiveness means that this represents a large potential transfer to small businesses. We assess the importance of the grant component of the CARES loans relative to a pure (and far less expensive) loan program. One-third of the survey respondents were randomly asked about their interest in a CARES-like program, which was describe as a loan program which "will be forgiven by the amount spent on payroll, lease, rent, mortgage, and utility payments in the 8 weeks after origination." One-third of the respondents were randomly 
asked about their interest in a loan program that was otherwise identical, but without prompting any possibility of forgiveness. ${ }^{\dagger \dagger}$ As part of the display, the amount of liquidity was varied, with the caveat to respondents that these policies may not be the actual policies currently available to them. This was designed to measure how program generosity affects take-up and perceived business resilience. + t+

Figure 10 shows the expected take-up of the two programs (the exact details of the question wording is contained in the Figure notes). Seventy-two percent of respondents who were told about the loans with forgiveness said that they would like to take them up. 59 percent of respondents were interested in taking up the loan program without forgiveness. While there was substantial interest in a pure-loan program, there was significantly more interest in the loan program with forgiveness.

A primary reason to forgive loans is that such a subsidy might do more to maintain employment and keep businesses open in the long-term. ${ }^{\S \S}$ We therefore re-asked businesses to project their likelihood of being open and their expectations about employment after we told them about the loan programs. Figures 11 and 12 show the expected probability of being open and the expected employment (relative to January 2020 employment) for the two groups of respondents.

Before they were told about the policies, both groups had experienced similar employment declines since January and both groups expected their employment in December 2020 to be about 40 percent less relative to January 2020 (that is, assignment was balanced). After the respondents were told about the CARES-like loans, they projected their employment would decline by only 6 percent by December 2020. The respondents who were told about loans without forgiveness predicted their employment levels would fall by 14 percent. $^{* * * *}$ We are

\footnotetext{
${ }^{++t}$ Because there was significant policy uncertainty at the time of the survey, one third of respondents were also asked about a potential policy that focused on aid that could only be used for payroll. This policy became less relevant after the details of the CARES act emerged.

${ }^{\ddagger \neq \ddagger} \mathrm{A}$ few program features differed between what was displayed to respondents and the actual program. The most relevant is that the interest rate displayed was $4 \%$, which was higher than the interest rate under the program for the non-forgiven portions of the PPP loans. This reflected the maximum interest rate in the legislative text of the CARES act. The actual implemented interest rates ended up below this maximum.

$\$ \$ \AA$ An exact welfare analysis is beyond the scope of this paper. Hamilton (2000) suggest that the median person in self-employment might be realizing non-pecuniary benefits because earnings differences may not justify the risk of running a business, but those who persist in self-employment over the long-run likely have a comparative advantage in running their own business relative to their other options (Dillon and Stanton, 2017). ${ }^{* * * *}$ Because we randomize the policy and the generosity, this analysis is equally weighted across firms.
} 
unable to distinguish precisely whether it is the conditional nature of the PPP program or the more favorable credit terms that drive these differences.

When asked about their expectation of remaining in business in December 2020, businesses responded similarly. Before being told about the loans, the businesses thought that they had a 62-63 percent chance of being open in December 2020. The probability rose to 81 percent among those who were told about the standard loans. The projected chance of survival increased to 85 percent for the businesses who were informed about the PPP loans that came with forgiveness. Again, the flow of credit seems important, but forgiveness did have a statistically significant impact on the expectation of staying in business.

Why would businesses not take the aid that comes with such generous forgiveness terms? Figure 13 asks the 28 percent of firms that said that they would not take a CARES-like loan why they would turn down such a generous offer. The most common response, given by 35 percent of refusers, was that they did not need the cash, which suggests that one-tenth of our sample truly feels confident with their financial security. ${ }^{\dagger \dagger \dagger \dagger}$

A significant number of those who said that they wouldn't take the CARES assistance cited other concerns. Thirty percent of these respondents said that they didn't think that they would qualify. Nearly twenty percent said that they didn't trust the government to forgive the debt. Over one-tenth thought that it would be too much of a hassle. These results suggest that clarity about the program and a streamlined process are important policy considerations to ensure a high take-up rate.

We also randomly informed survey recipients about the changes in unemployment insurance under the CARES act. We found that informing employers about the increased generosity of unemployment insurance was associated with lower employment projection in December 2020, among those businesses that were told about the CARES-like loans. Information about unemployment insurance had no impact on the expected probability of remaining open. More work is needed to understand how interactions between programs may influence economic outcomes.

\footnotetext{
tit Those who report their intention not to take-up the program due to having sufficient cash have a median of 3.5 months of cash on hand. Those who express other reasons for lack of take-up have a median of 1 month of cash.
} 


\section{Industry Differences in Response to Crisis Duration}

COVID-19 disruptions do not affect all businesses equally. Some are deemed essential and remained open, while others were forcibly shutdown. Some businesses could reduce contagion risk among employees through a shift to remote work while other businesses were illequipped for the transition. For a variety of reasons related to both the underlying nature of the business and management capacity, COVID-19 appeared to be an existential threat to some businesses at the time of the survey.

Disparities between businesses appear most stark when we measure their response to extended durations of the pandemic. In our survey, we ask the following hypothetical: "We want to understand how the duration of the COVID-19 disruptions might change your answers. Suppose that most COVID-19 disruptions continue for X months, what is the likelihood of your business remaining operational by Dec. 31, 2020? Please provide your best guess." We randomize the duration $(\mathrm{X})$ to be 1 month, 4 months or 6 months, and offer respondents a 5-point scale ranging from extremely unlikely to extremely likely. As before, we transform this answer into a binary outcome of likely or unlikely to remain open for ease of exposition.

Table 5 displays the responses to this question by industry. When firms are told to expect a one-month crisis, the expectation of remaining open by the end of the 2020 hovers above 68 percent across all industries with the exception of Arts and Entertainment, Personal Services, and Tourism and Lodging. In those industries, the expectation of remaining open drops to 66 percent, 57 percent, and 63 percent respectively.

When firms are told to expect a six-month crisis, the average expectation of remaining open falls to 39 percent, and there is significant heterogeneity between sectors. The expected survival probability for firms in Arts and Entertainment drops precipitously to 45 percent under a 4-month crisis, and 35 percent if the crisis lasts 6 months. The expected probability of being open for Personal Services firms falls to 19 percent if the crisis lasts six months.

The restaurant industry also seems particularly vulnerable to a long crisis. Restaurateurs believed that they had a 74 percent chance of survival if the crisis lasts one month, but if the crisis lasts four months, they gave themselves a 29 percent chance of survival. Under a sixmonth crisis, they expected to survive with only a 19 percent probability. Likewise, the chance of survival for firms in tourism and lodging drops to 25 percent by the 6-month mark. Meanwhile, 
Banking and Finance, Real Estate and Professional Services reported they will be able to weather extended disruptions far better than these more exposed sectors.

In Table 6, using the results in Table 5 around closure probabilities as a function of crisis duration, we examine how employment separations might evolve due to firm closure. Building on our estimates of the impact of crisis duration on job loss, Table 6 estimates the impact of COVID-19 on aggregate job loss from small business closures and how businesses expected this to vary with crisis duration. Specifically, we begin with the number of workers who are projected to lose their jobs from small firm closures. We then multiply the initial employment level (based on the 2017 Economic Census), at the employment size level, by the survey-based estimate of the share of firms that will be closed in December depending on the length of the crisis. The first row shows that there were 5.9 million workers in firms with fewer than five employees in 2017. In our survey, 43 percent of those smaller firms expected to be closed in December even if the crisis lasted for only one month. Next, we multiplied .43 times 5.9 million workers to project 1.6 million separations due to firm closings (in the absence of additional aid beyond what was expected at the time of the survey). These smaller firms are extremely fragile, but since they represent a relatively small share of employment, their closures add only modestly to overall job losses. Firms with over 50 employees are more optimistic about their survival, even if the crisis lasts for several months. Yet even among these firms, 54 percent expected to be closed in December if the crisis lasts at least four months. Those closures would create 14.6 million separations. This figure may be an overestimate, because this firm size category is large and the closure rates may be lower for larger firms.

Taken altogether, the closures are projected to create 32.7 million job losses if the crisis lasts for four months and 35.1 million job losses if the crisis lasts for six months. Moreover, these job losses look only at business closures and do not account for the reduction in the number of workers by firms that remain open or job losses among workers who are employed by larger firms.

These results suggest that the damage to our economy and its network of small businesses will be far larger if the crisis lasts for many months. This suggests large potential economic benefits for policies that can safely lead to reopening the economy quickly.

\section{Conclusion}


Small businesses employ almost fifty percent of American workers. Yet, our results underscore the financial fragility of many small businesses, and how deeply affected they are by the current crisis. In our sample, which is skewed toward the retail sector, we found that 43 percent of businesses were temporarily closed and that employment had fallen by 40 percent. This represents a shock to America's small firms that has little parallel since the Great Depression of the 1930s. Our results suggest that many of these firms had little cash on hand toward the beginning of the pandemic, which means that they will either have to dramatically cut expenses, take on additional debt, or declare bankruptcy. This highlights the ways in which the immediacy of new funding might impact medium term outcomes.

Small businesses' responses to our survey suggest that many are likely to fail absent financial assistance. As of the last week of March 2020, 38 percent of businesses viewed it as unlikely or only somewhat likely that they would be open as of the end of 2020. While optimism increased when they were informed about the CARES loan program, it is unclear whether the CARES act will enable most of America's small businesses to survive - or whether beliefs about its impact are overly optimistic.

The results also highlight the importance of well-designed and sustained economic and public health policy measures. Three policy-relevant results of our survey stand out. First, more than 13 percent of respondents say that they do not expect to take out CARES Act PPP loans because of the application hassle, distrust that the federal government will forgive the loans, or worry about complicated eligibility rules. Therefore, streamlining the application process and clarifying the eligibility criterion and loan forgiveness rules might increase the take-up rate for loans. Second, firms in particularly exposed industries - such as restaurants, tourism, and personal services - project that they will find it extremely difficult to stay in business if the crisis lasts for longer than four months. These findings suggest large economic benefits from any policies that can safely shorten the economic shutdown (e.g. through stronger short-term containment policies). Third, if we extrapolate the 72 percent of businesses who indicate they would take up the CARES PPP loans to all US small businesses, the total volume of loans would be approximately $\$ 410$ billion. $1+$ When we allow for different take-up rates by employer size and multiply by the 2017 Census payroll amounts in each firm size category, we estimate total loan demand of $\$ 436$ billion, in excess of the $\$ 349$ billion allocated in the first tranche of the

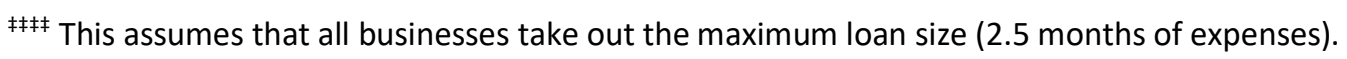


CARES act..$^{\S \S \S}$ Total demand for such aid may ultimately be even higher under an extended crisis.

$\S \S \S$ Monthly payroll in the 2017 Census data for businesses under 500 employees totaled 226 billion dollars. Our estimates do not account for increases in total payroll in this sector since 2017. Our estimates also do not account for the fact that the PPP guidelines allowed some firms with more than 500 employees to access aid. 


\section{References}

Altig, D., J. Barrero, N. Bloom, S. Davis, B. Meyer, E. Mihaylov, and N. Parker (2020, May). COVID-19 Caused 3 New Hires for Every 10 Layoffs. Atlanta Fed Blog, May 1, 2020.

Barro, R. J., J. F. Ursúa, and J. Weng (2020, March). The coronavirus and the great influenza pandemic: Lessons from the "Spanish flu" for the coronavirus's potential effects on mortality and economic activity. Working Paper 26866, National Bureau of Economic Research.

Bazerman, M. and D. Moore (1994). “Judgment in Managerial Decision Making” Wiley Publishing.

Bettinger, E., B. Long, P. Oreopoulos, and L. Sanbonmatsu (2012). The Role of Application Assistance and Information in College Decisions: Results from the H\&R Block Fafsa Experiment. The Quarterly Journal of Economics.

Bloom, N., Eifert, B., Mahajan, A., McKenzie, D., \& Roberts, J. (2013). Does management matter? Evidence from India. The Quarterly Journal of Economics, 128(1), 1-51.

Cajner, T., L. Crane, R. Decker, J. Grigsby, A. Hamins-Puertolas, E. Hurst, C. Kurz, and A. Yildirmaz (2020). The U.S. Labor Market during the Beginning of the Pandemic Recession. Working paper.

Collins, B., Garin, A., Jackson, E., Koustas, D., \& Payne, M. (2019). Has the Gig Economy Replaced Traditional Jobs Over the Last Two Decades? Evidence from Tax Returns."

DellaVigna, S. and M. Gentzkow. (2019). Uniform pricing in us retail chains. The Quarterly Journal of Economics.

Dillon, E.., and C. Stanton. (2017) Self-employment Dynamics and the Returns to Entrepreneurship. Working Paper 23168, National Bureau of Economic Research.

Faulkender, M. (2002). Cash Holdings Among Small Businesses. Working paper.

Finkelstein, A. and M. Notowidigdo. (2019). Take-Up and Targeting: Experimental Evidence from SNAP. The Quarterly Journal of Economics.

Garrett, T. A. (2007). Economic Effects of the 1918 Influenza Pandemic: Implications for a Modern-Day Pandemic. Federal Reserve Bank of St. Louis.

Garrett, T. A. (2008). Pandemic economics: the 1918 influenza and its modern-day implications. Federal Reserve Bank of St. Louis Review 90(Mar), 74-94.

Goldfarb, A. and M. Xiao (2011). Who Thinks about the Competition? Managerial Ability and Strategic Entry in US Local Telephone Markets. American Economic Review 
Hamilton, Barton H. (2000) "Does entrepreneurship pay? An empirical analysis of the returns to self-employment." Journal of Political Economy 108, no. 3: 604-631.

La Rocca, M., R. Stagliano, T. La Rocca, A. Cariola, and E. Skatova. (2019) Cash holdings and SME performance in Europe: the role of firm-specific and macroeconomic moderators. Small Business Economics.

Strulov-Shain, A. (2019). More than a Penny's Worth: Left-Digit Bias and Firm Pricing, working paper.

\section{Appendix}

Appendix 1: Initial message shown to respondents

Thank you in advance for your participation in our survey!

Academics from Harvard University and the University of Chicago are looking to better understand the impact the coronavirus is having on the local business ecosystem - and what can be done to help local businesses. We hope that it will help to communicate your current needs to policymakers.

Please share your truthful and considered views. Your individual answers will be completely confidential.

Sincerely,

Zoe Cullen and Chris Stanton

Professors of Business Administration

Harvard Business School 
Tables and Figures

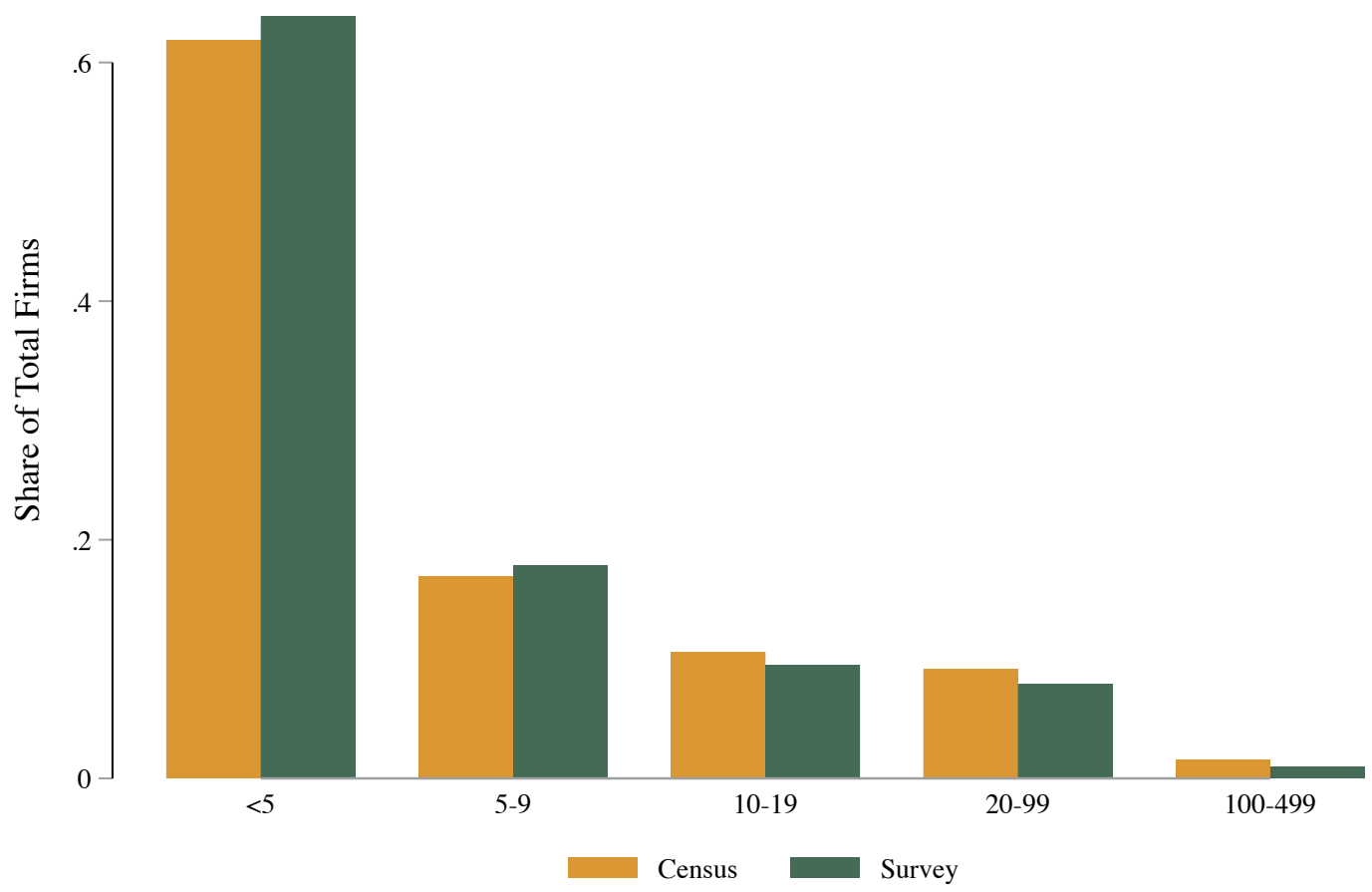

Figure 1: Firm Size in the Survey and Census

This figure plots the share of firms in each employment category for the 2017 Census of US Businesses and the survey respondents. The sample size for the survey is 4,873 responses, omitting 959 responses with missing employment data. 


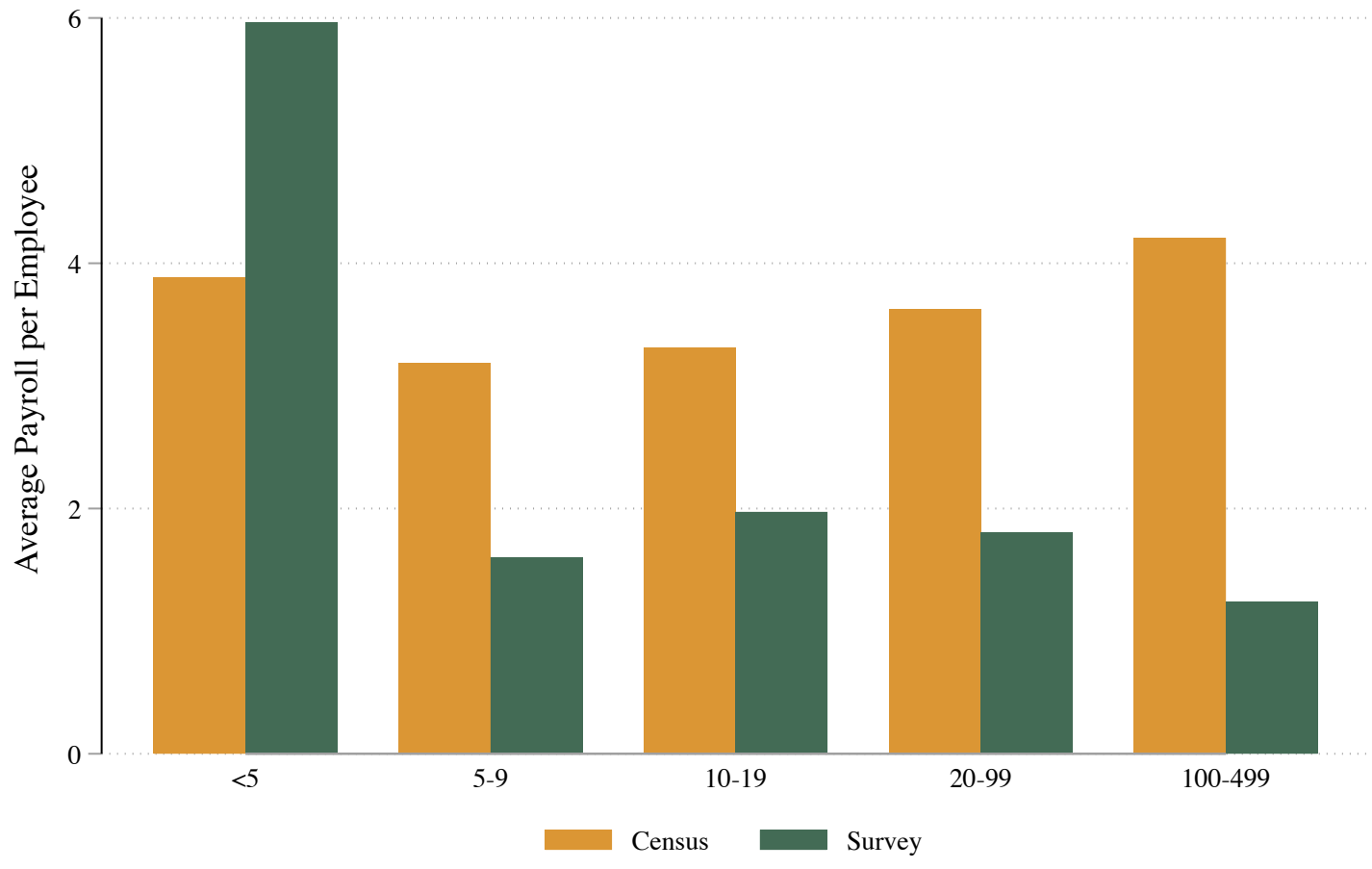

Figure 2: Average Per Capita Payroll (\$ 1000s) in the Survey and Census

This figure plots per-employee payroll in thousands of dollars by firm size for the 2017 Census of US Businesses aggregates and the survey respondents. The Census data only reports annual payroll for W2 workers and the number of firms in an employment size category. To calculate payroll for the survey firms, we take the midpoint of categorical answers for monthly expenses, multiply by the fraction of expenses going toward payroll and divided by total employees (we cannot distinguish between W2 employees and contractors). 


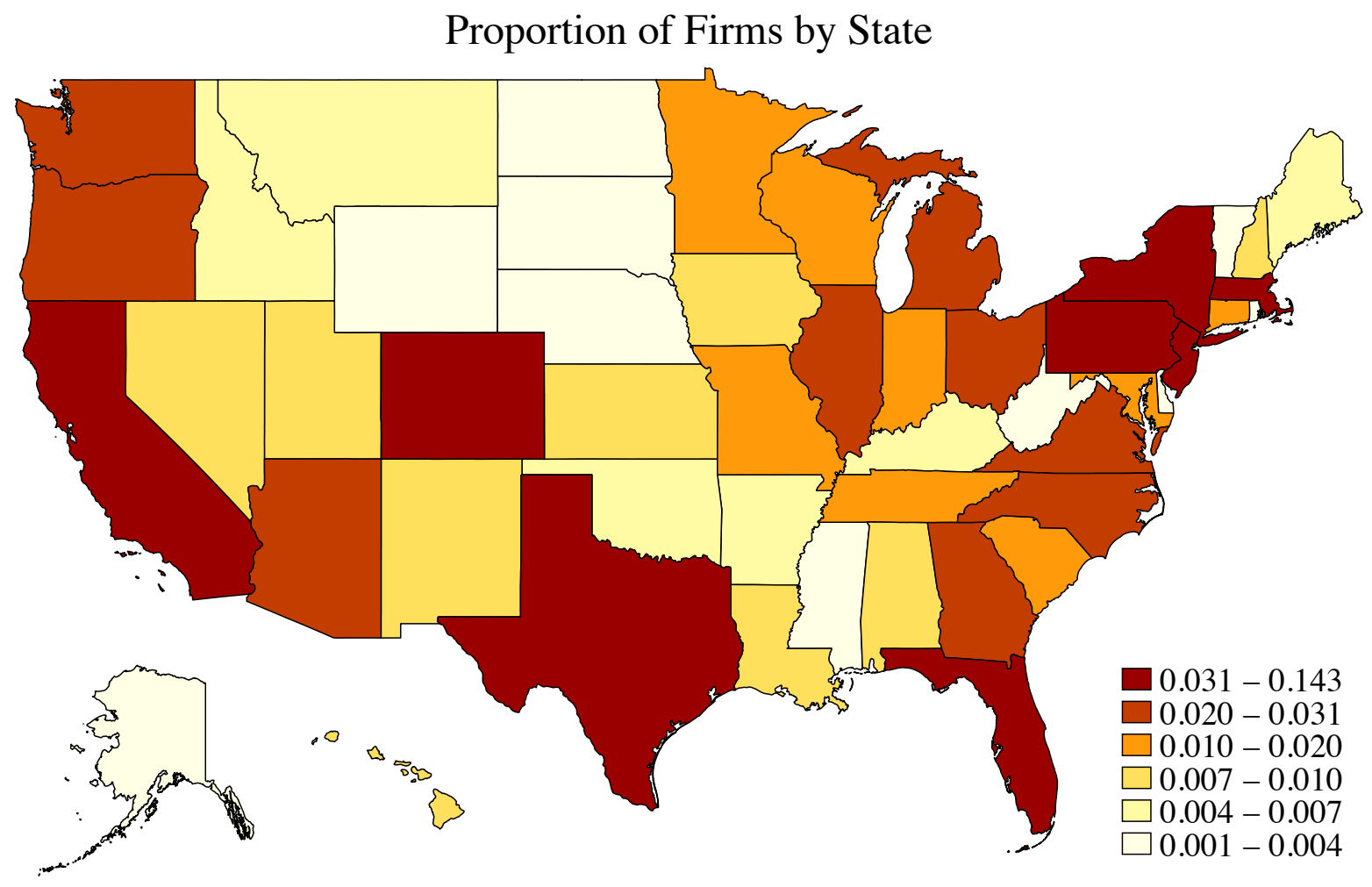

Figure 3: Coverage by State

This figure plots shares of survey responses across different states. 


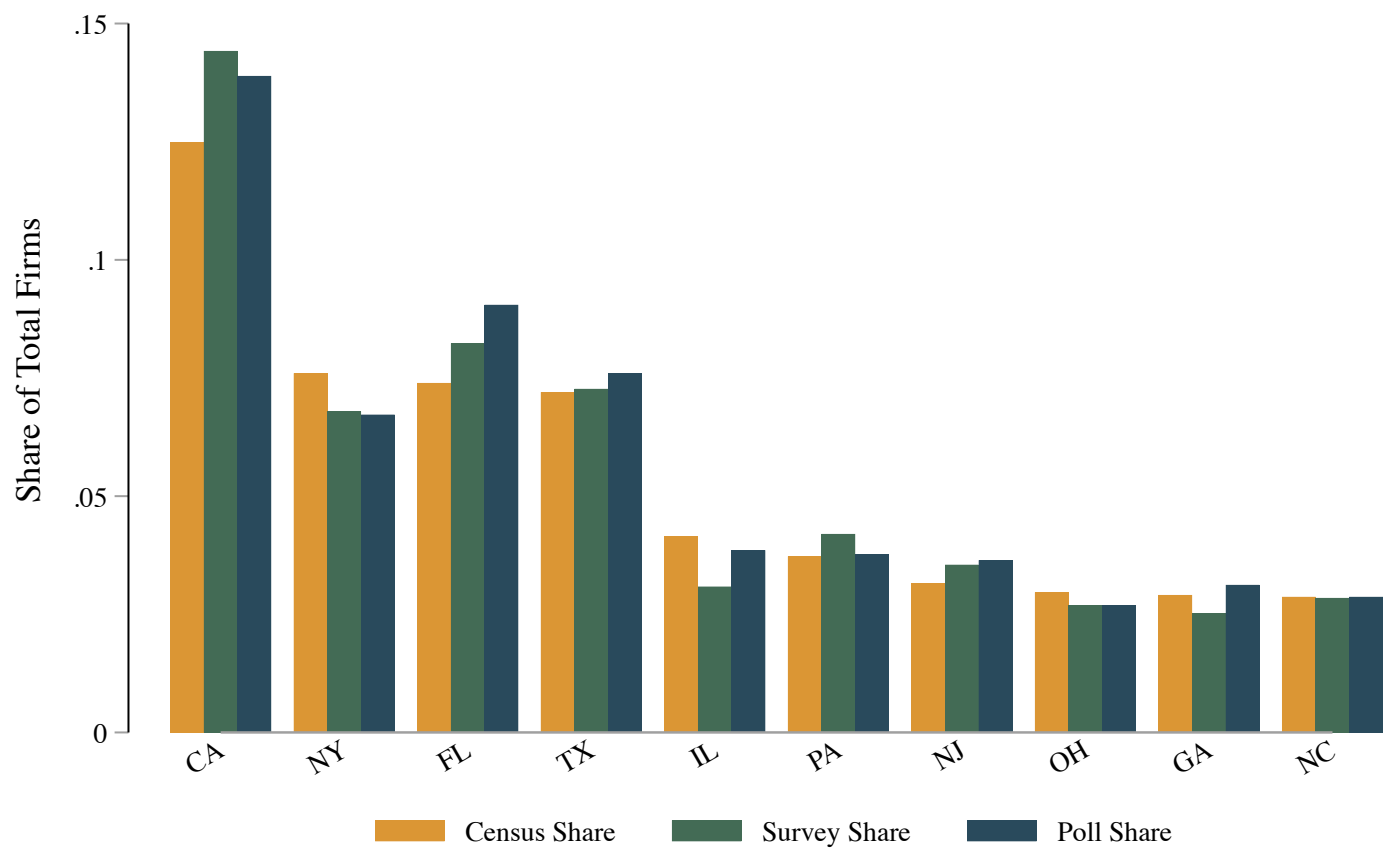

Omits responses with missing location data.

Figure 4: Firm Size in the Census, Downstream Survey, and Upstream Pre-Survey Alignable Poll

This figure plots the share of firms in each state for the 2017 Census of US Businesses, the survey respondents, and the respondents who took the upstream Alignable poll. Users who took the survey did so after taking the Alignable poll. They were then re-directed to the HBS Qualtrics web link. Note that the upstream poll did not ask questions about firm size or payroll, so prior figures cannot check compositional differences based on firm size or pay. 
Histogram of Approximate Months of Cash Available

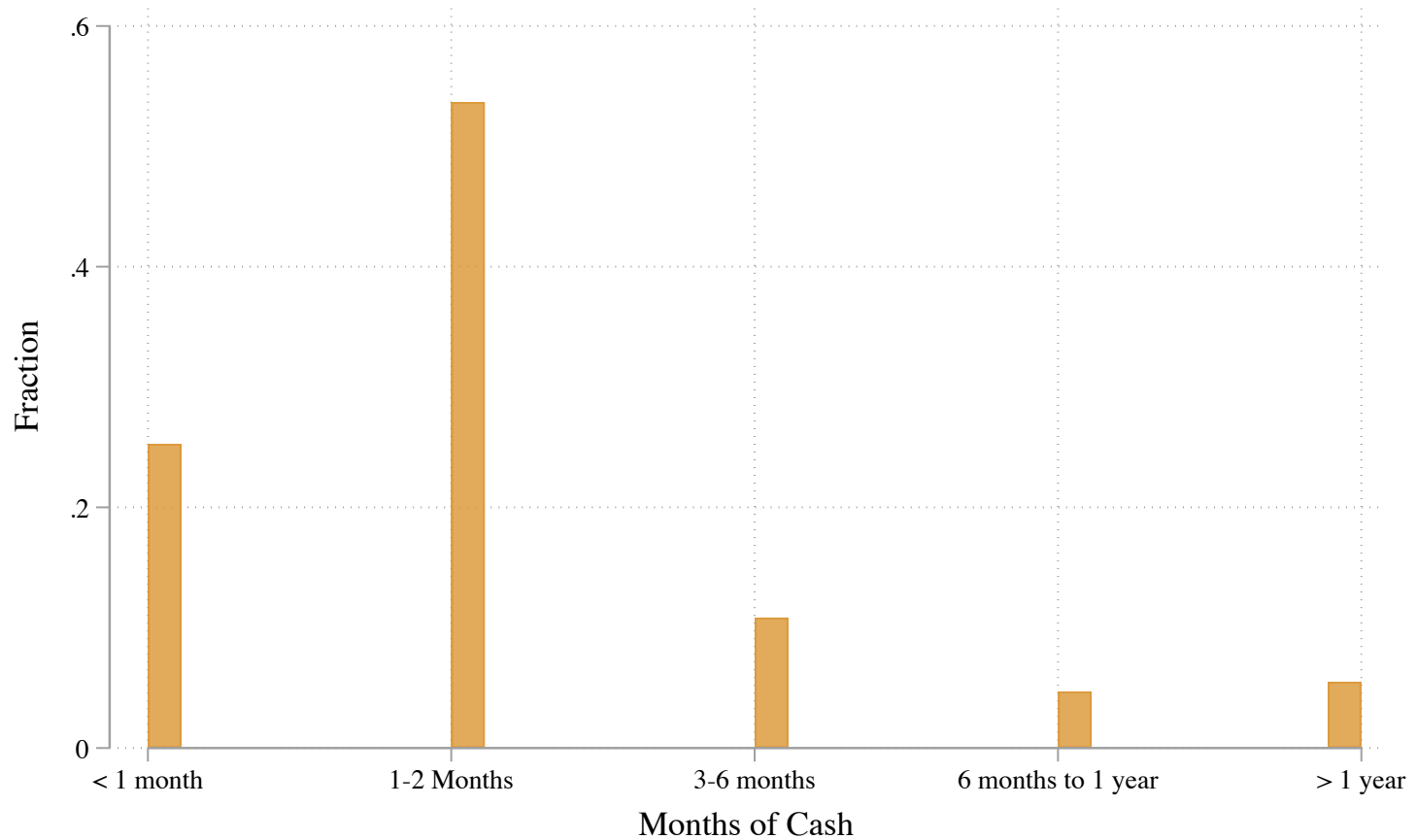

Figure 5: MONTHS OF CASH

This figure plots firms' months of cash available as a multiple of January 2020 expenses. We compute this measure by taking the midpoint of categorical responses for the amount of cash on hand and divide by the midpoint of the categorical response for typical monthly expenses prior to the crisis. The sample size is 4,176 . 


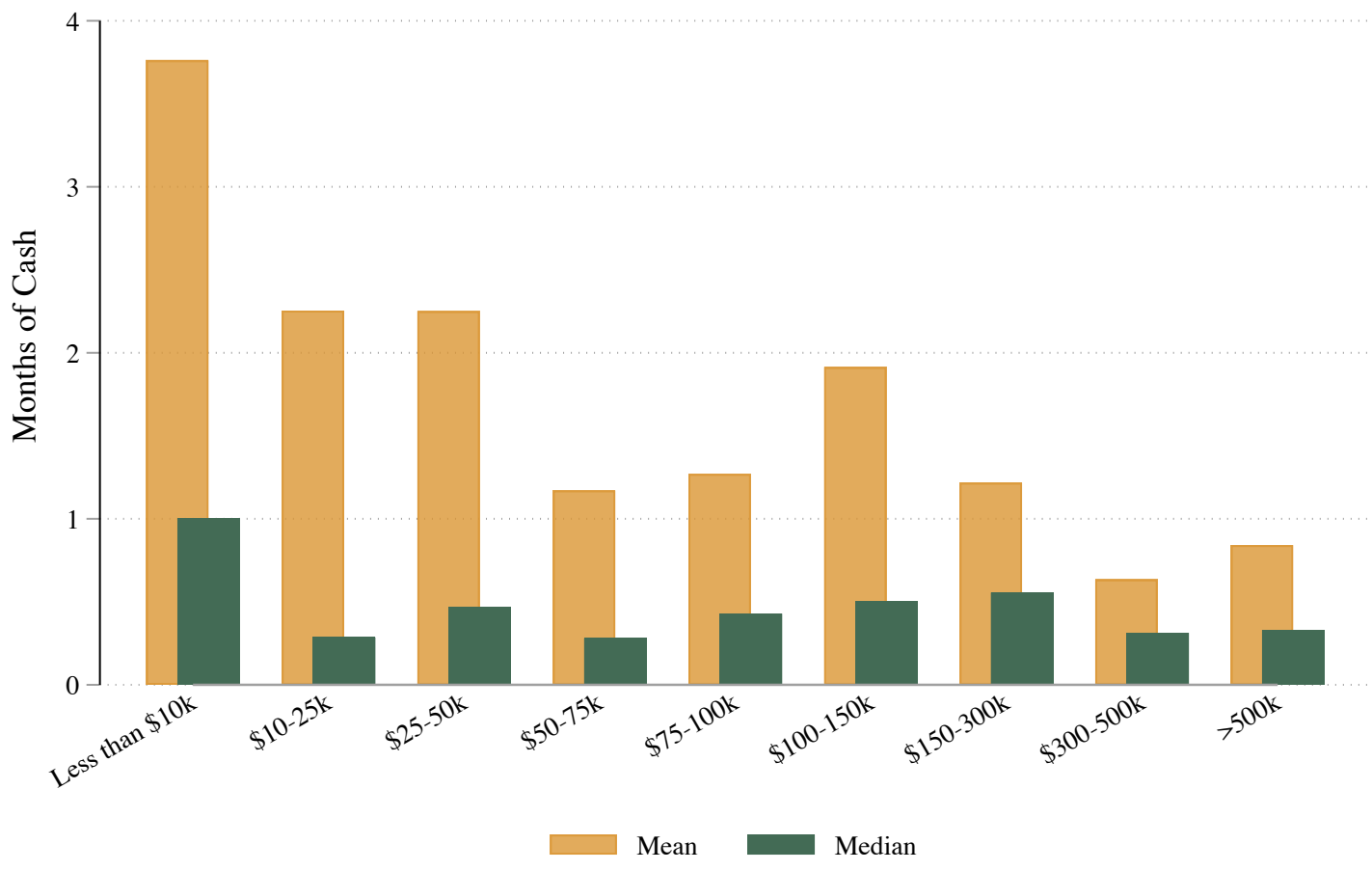

Figure 6: Mean and Median Months of Cash Split by Monthly Expenses \$000s

This figure plots means and medians of the months of cash available measure across the distribution of typical monthly expenses. 
Fraction Who Believe Crisis Will End Before Each Date

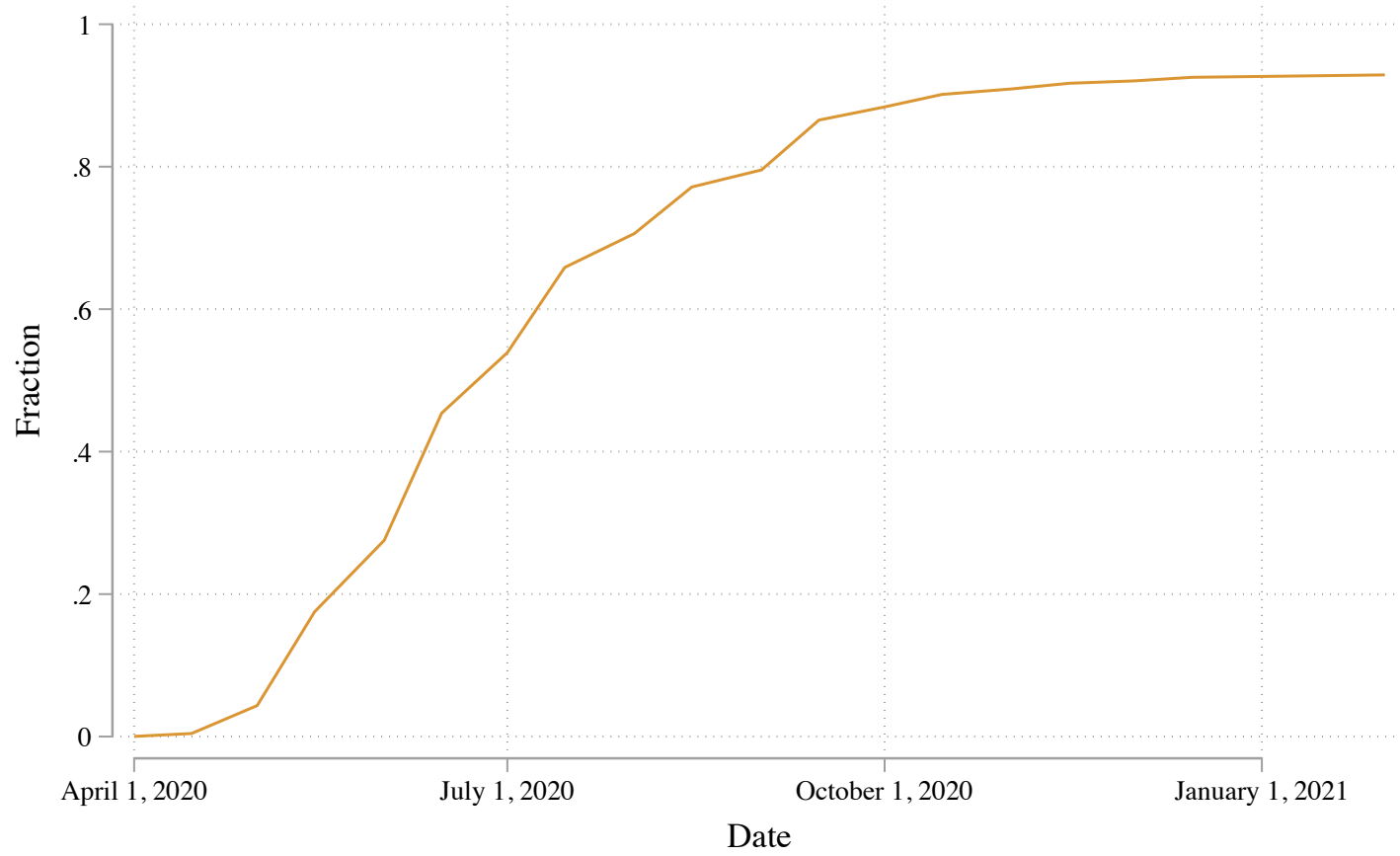

Figure 7: CDF of Expected COVID End Date

This figure plots the distribution function across respondents for the expected end date of COVID related disruptions. The $\mathrm{y}$-axis represents the share of respondents who believe that COVID disruptions will end on or before the date given on the $\mathrm{x}$-axis. 
Likelihood of Being Open on Dec 31, 2020

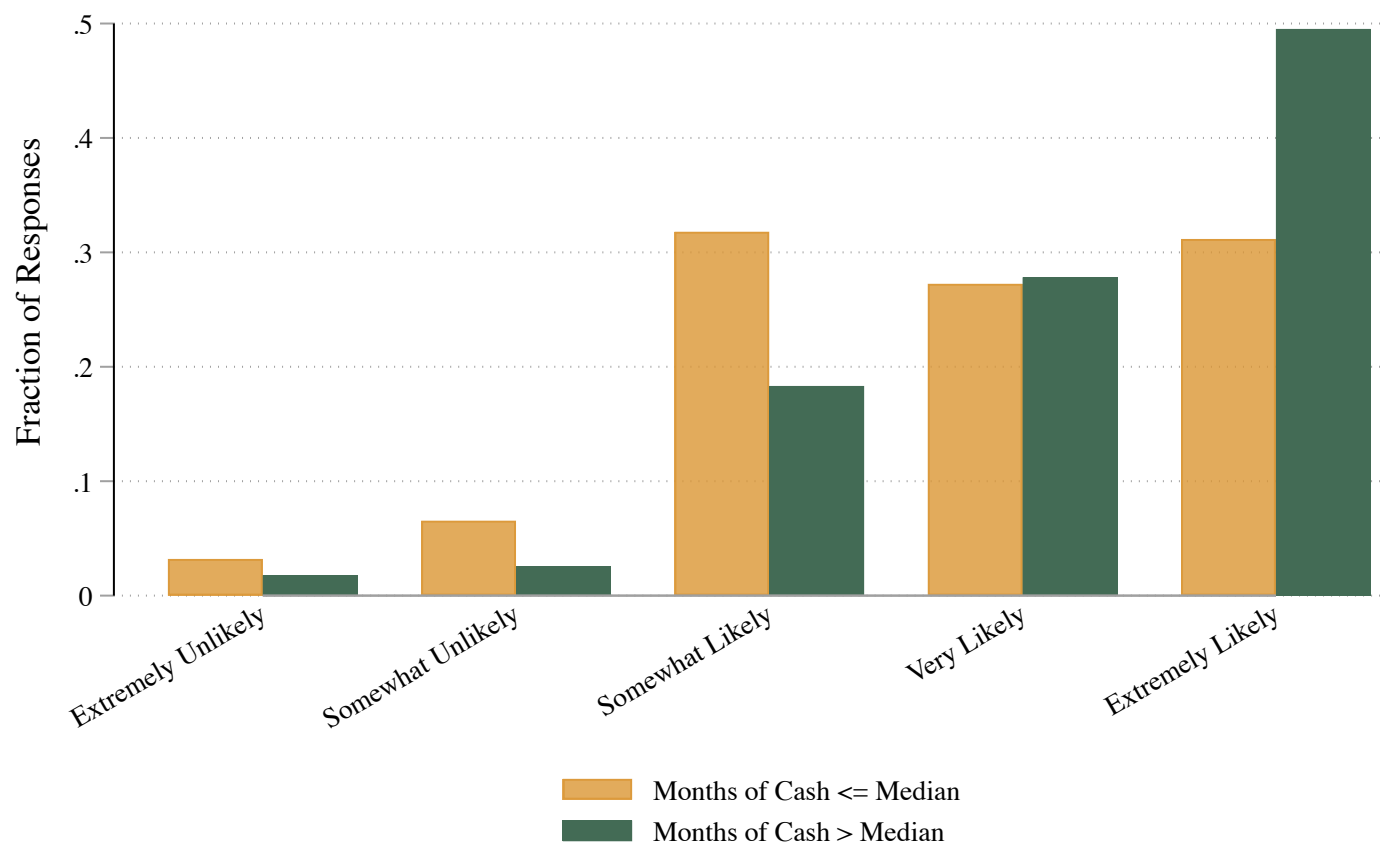

Figure 8: Likelihood of Remaining Open or Re-Opening by December

This figure displays the frequency of answers to a question about the likelihood of being open in December, 2020. Responses are plotted based on whether the firm has more than the median number of months of cash on hand given their pre-COVID expenses. 


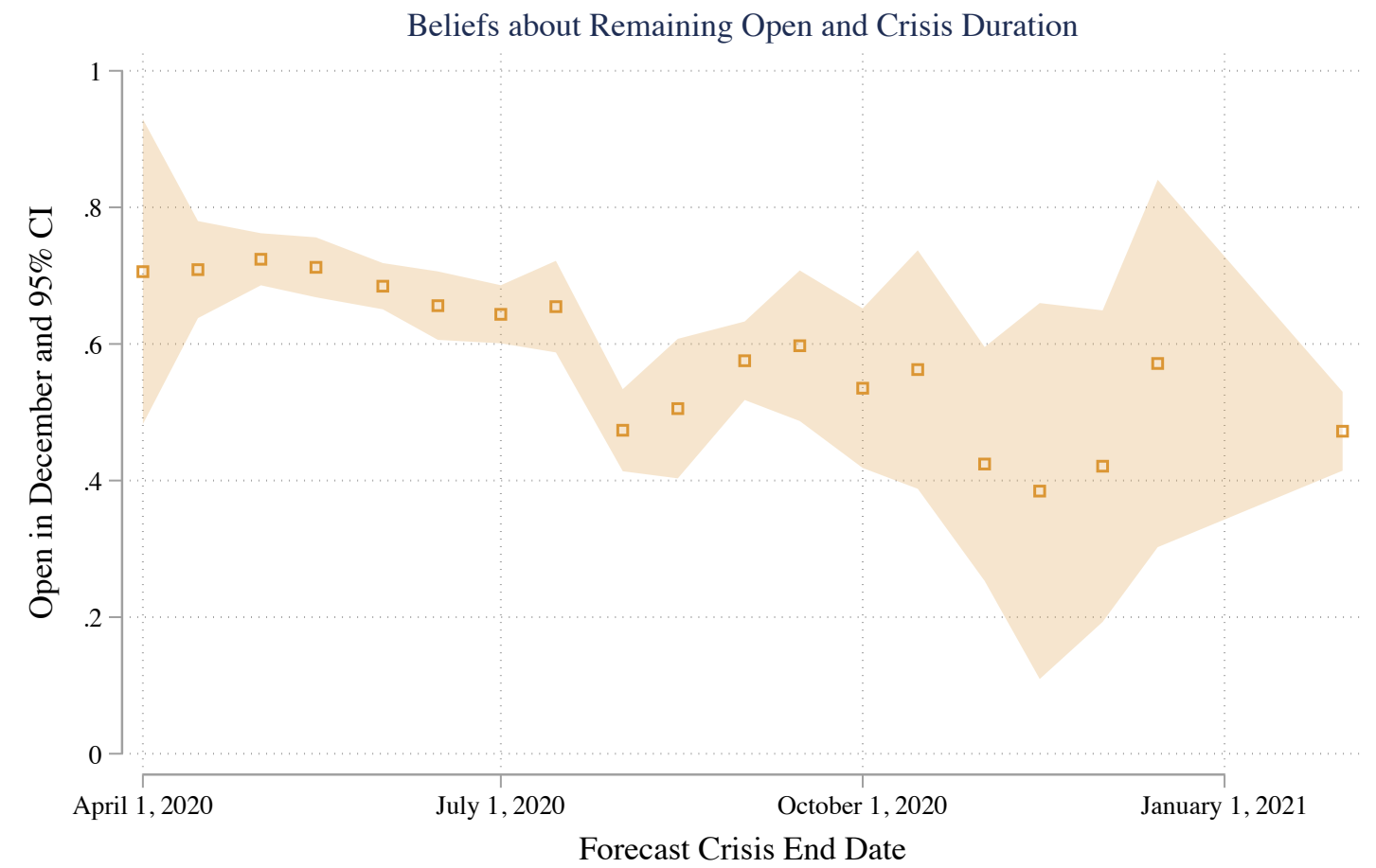

Figure 9: Likelihood of Remaining Open or Re-Opening by December, 2020 as a FuncTiOn of Beliefs about COVID End Date

This figure plots the likelihood of being open in December, 2020 as a function of respondents' expected COVID end date. Averages are plotted and the shaded region is the confidence interval. The opening likelihood is computed as the share of respondents who answered "Extremely likely" or "Very likely." 


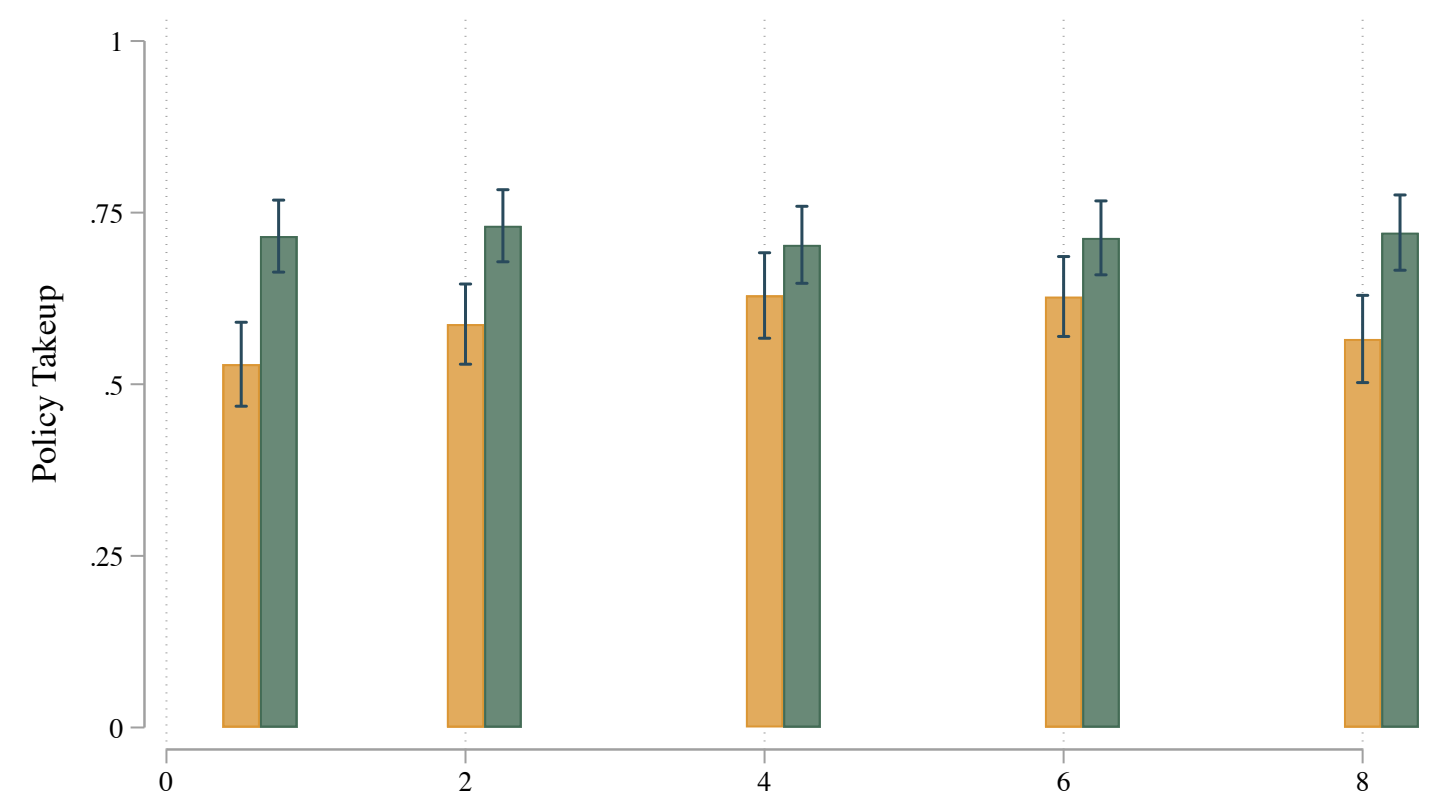

Borrowing Base as a Multiple of Monthly Expenses

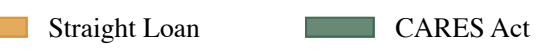

Figure 10: Differences in Policy Take-up Across Loans versus CARES Act PPP Program Split by Hypothetical Limits on Borrowing Amount

This figure displays policy take-up rates for loans versus the stylized Paycheck Protection Program policy using a between subjects design. The borrowing base was also randomized between subjects as a multiple of typical monthly expenses prior to the crisis. The text displayed for the PPP program was: "Imagine a policy where the government allows you to borrow up to [borrowing base] times your typical monthly expenses without posting any collateral. You could use this money to cover any of your business expenses. The loan will be forgiven by the amount spent on payroll, lease, rent, mortgage, and utility payments in the 8 weeks after origination (you can consider this amount to be a grant). The remainder of the loan (that is not spent on these items) will have deferred payments for 1 year. After that, the loan would have an annual interest rate of $4 \%$ (deferred for 1 year) and you would have up to 10 years to repay the loan. For example, if you borrow $\$ 50,000$ and you have no qualifying expenses to offset the loan, the required monthly payment starting 1 year from today would be $\$ 506$ per month for 10 years. If you borrow $\$ 50,000$ and spend $\$ 40,000$ to pay your employees during the first 8 weeks, you will have 10 years to pay the remaining $\$ 10,000$ with monthly payments of $\$ 102$." Subjects in the loan condition saw the text: "Imagine the government offers a loan allowing you to borrow up to [borrowing base] times your typical monthly expenses without posting any collateral. You could use this money to cover any of your business expenses. The loan would have an annual interest rate equivalent of $4 \%$ and principal and interest payments would be deferred for 1 year. You would have up to 10 years to repay the loan. For example, if you borrow $\$ 50,000$, the required monthly payment starting 1 year from today would be $\$ 506$ per month for 10 years." Pooled means for the loan and CARES act responses are 0.59 and 0.72 , respectively. The sample size is 2,610 and the pooled t-statistic on the difference between policies is 6.97 . 


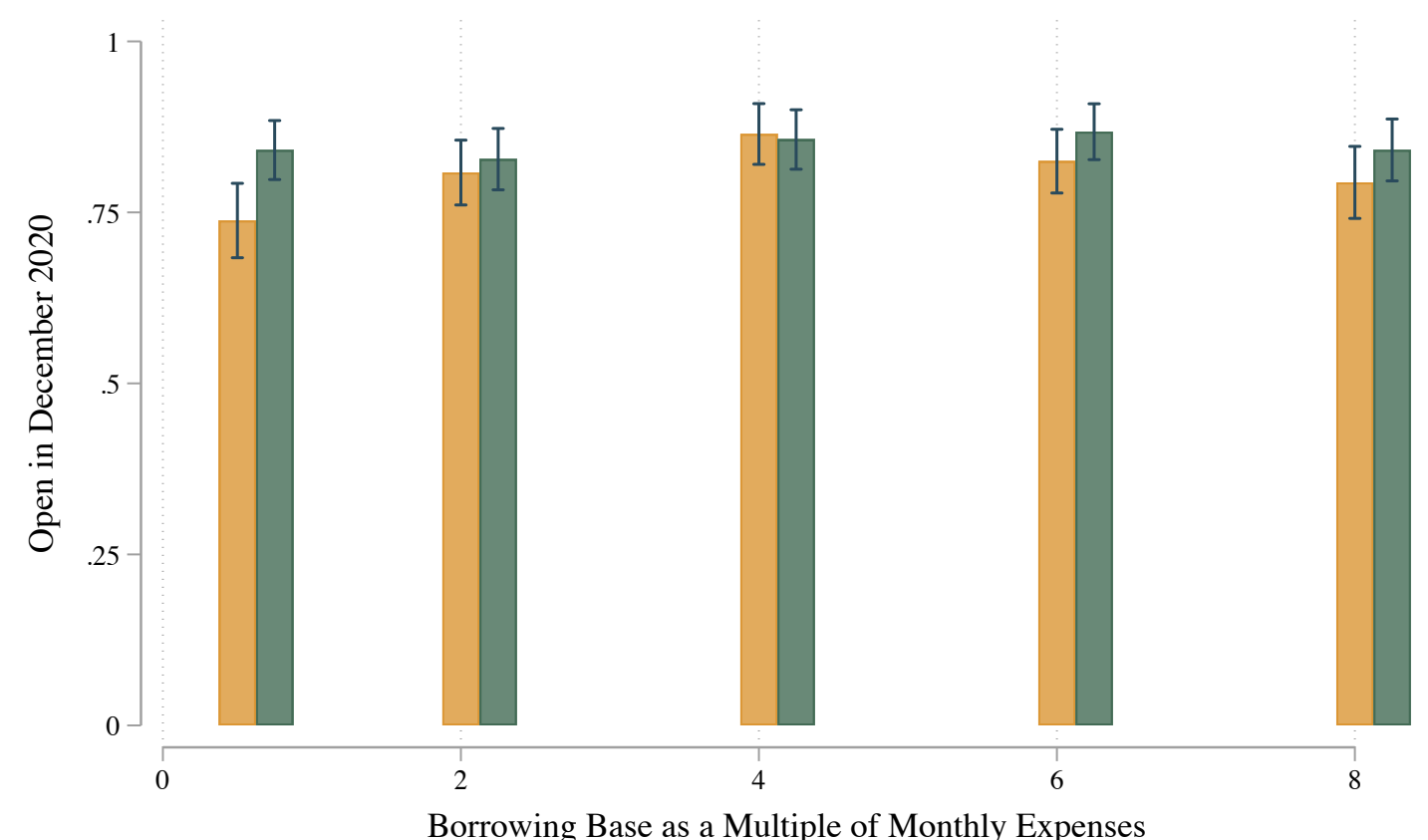

Borrowing Base as a Multiple of Monthly Expenses

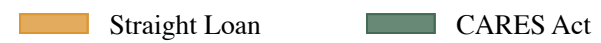

Figure 11: Differences in Policy Effects on the Propensity to Remain Open in DeCember of 2020, Split by Hypothetical Limits on Borrowing Amount

This figure plots differences in the propensity to remain open under different policies. The measure is computed using a follow-up question after policy information displayed, using the fraction that chose "Very likely" or "Extremely likely" to be open in December of 2020. See notes for Figure 10 for additional detail about the policy display. Pooled means for the loan and CARES act are 0.805 and 0.848 , respectively. The sample size is 2,550 and the pooled t-statistic on the difference between policies is 2.76 . 


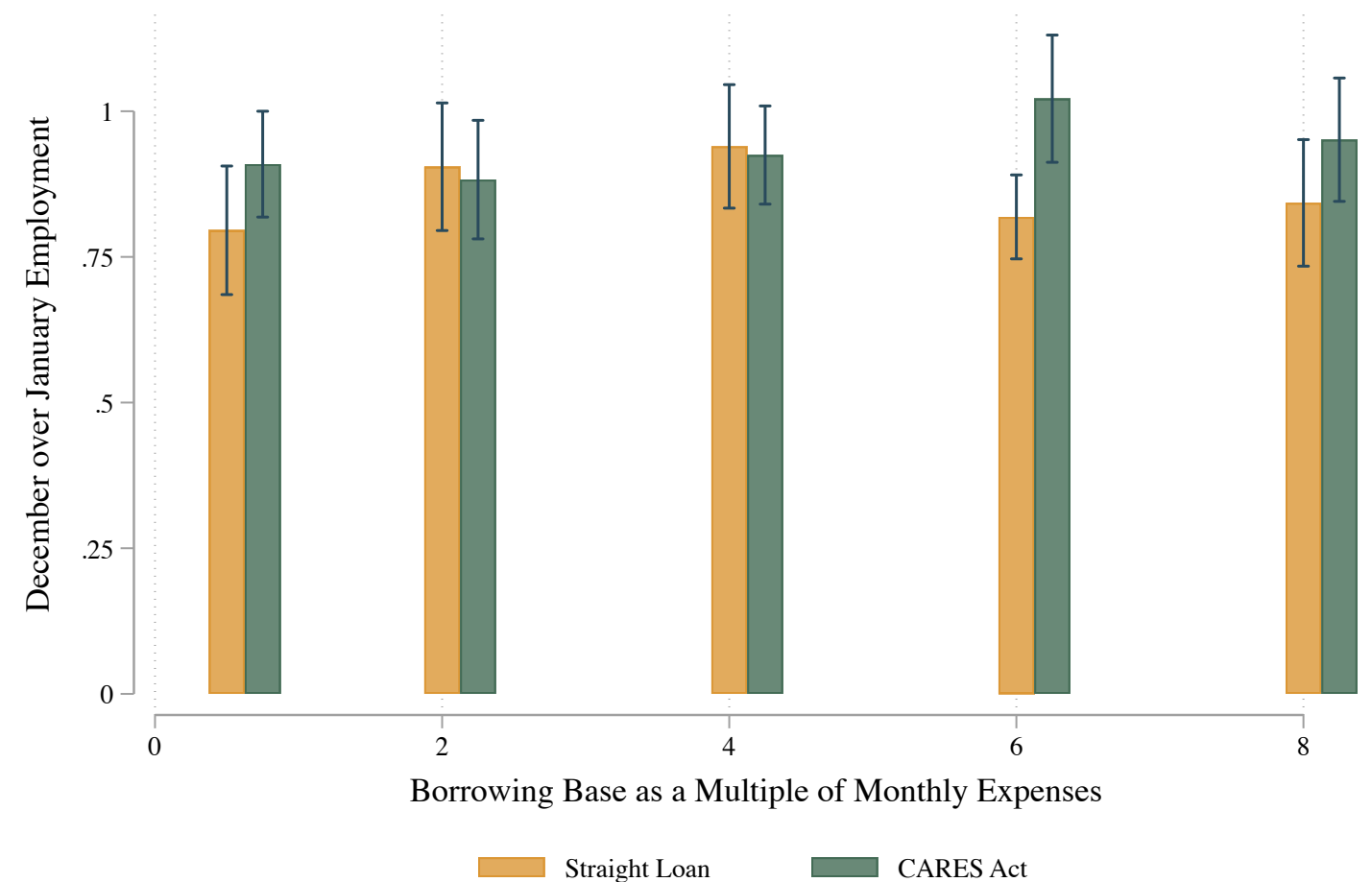

Figure 12: Differences in Policy Effects on Relative Employment Between December AND JANUARY

This figure plots differences in the ratio of relative employment between December 2020 and January 2020 under different policies. The December 2020 employment measure is computed using a follow-up question after policy information displayed. See notes for Figure 10 for additional detail about the policy display. Pooled means for the loan and CARES act responses are 0.86 and 0.94 , respectively. The sample size is 2,341 and the pooled t-statistic on the difference between policies is 2.42 . 


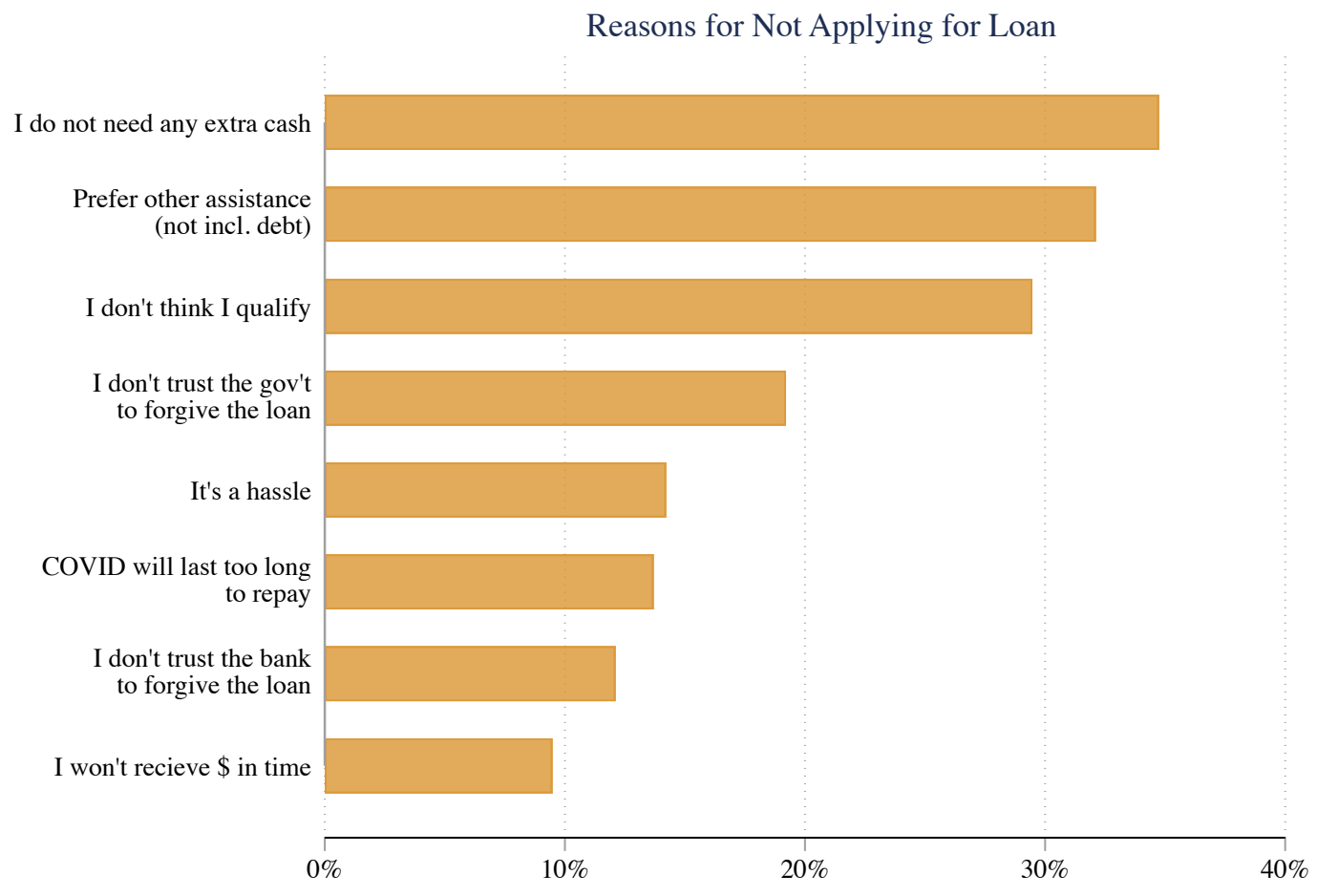

Figure 13: Reasons For Not Using the Resources in the CARES Act

This figure contains the frequency of responses for reasons that respondents would not take-up aid under the CARES Act policy condition. 383 respondents indicated they would not use the policy and 382 answered this question. Respondents could select more than one option, so percentages need not sum to 100 . $50 \%$ of respondents selected an additional reason not displayed or filled in the free text entry for other. 
Table 1: Summary Measures Across Regions

\begin{tabular}{lcccccccc}
\hline \hline & \multicolumn{2}{c}{ Closed } & \multicolumn{2}{c}{ Expected to Close } & \multicolumn{2}{c}{ Weeks COVID } & \multicolumn{2}{c}{ Current / Jan } \\
& at Time & \multicolumn{2}{c}{ by December } & \multicolumn{2}{c}{ Will Last } & \multicolumn{2}{c}{ Employment } \\
& Mean & SD & Mean & SD & Mean & SD & Mean & SD \\
\hline East North Central & 0.45 & 0.50 & 0.35 & 0.48 & 14.7 & 10.2 & 0.68 & 0.38 \\
East South Central & 0.41 & 0.49 & 0.36 & 0.48 & 16.3 & 11.5 & 0.57 & 0.49 \\
Mid Atlantic & 0.54 & 0.50 & 0.37 & 0.48 & 14.5 & 10.0 & 0.53 & 0.45 \\
Mountain & 0.39 & 0.49 & 0.35 & 0.48 & 16.0 & 11.3 & 0.68 & 0.38 \\
New England & 0.47 & 0.50 & 0.33 & 0.47 & 16.6 & 10.2 & 0.55 & 0.49 \\
Pacific & 0.46 & 0.50 & 0.37 & 0.48 & 15.4 & 10.7 & 0.55 & 0.48 \\
South Atlantic & 0.41 & 0.49 & 0.38 & 0.48 & 15.5 & 10.3 & 0.63 & 0.45 \\
West North Central & 0.43 & 0.50 & 0.35 & 0.48 & 15.7 & 10.8 & 0.66 & 0.41 \\
West South Central & 0.40 & 0.49 & 0.39 & 0.49 & 15.2 & 11.1 & 0.68 & 0.43 \\
Total & 0.45 & 0.50 & 0.37 & 0.48 & 15.4 & 10.6 & 0.61 & 0.45 \\
N & 4976 &. & 4059 &. & 4162 &. & 4365 &. \\
\hline
\end{tabular}

Notes. This table reports breakdowns by regions. Totals include 12 observations with unknown region. Note that the Closed at Time column includes both temporary and permanent closures. The measure Expected to Close by December comes from a question asking about the likelihood of being open in December, where answers were given on a 5 point scale. Closure is coded as a binary indicator for those marking "Extremely Unlikely," "Somewhat Unlikely," or "Somewhat Likely" to be open in December. The ratios of current employment versus January employment are weighted by January employment. 
Table 2: Summary Measures by Firm Size

\begin{tabular}{lcccccccc}
\hline \hline & \multicolumn{2}{c}{ Closed } & \multicolumn{2}{c}{ Expected to Close } & \multicolumn{2}{c}{ Weeks COVID } & \multicolumn{2}{c}{ Current / Jan } \\
& at Time & \multicolumn{2}{c}{ by December } & \multicolumn{2}{c}{ Will Last } & \multicolumn{2}{c}{ Employment } \\
& Mean & SD & Mean & SD & Mean & SD & Mean & SD \\
\hline Under 5 & 0.46 & 0.50 & 0.36 & 0.48 & 15.8 & 10.9 & 0.66 & 0.49 \\
$5-9$ & 0.47 & 0.50 & 0.39 & 0.49 & 14.7 & 10.2 & 0.52 & 0.44 \\
$10-19$ & 0.41 & 0.49 & 0.42 & 0.49 & 14.7 & 10.1 & 0.55 & 0.47 \\
$20-99$ & 0.36 & 0.48 & 0.30 & 0.46 & 14.1 & 9.5 & 0.58 & 0.42 \\
$100-499$ & 0.26 & 0.44 & 0.22 & 0.42 & 16.2 & 10.8 & 0.72 & 0.44 \\
Unknown & 0.41 & 0.49 & 0.49 & 0.50 & 16.7 & 10.5 &. &. \\
Total & 0.45 & 0.50 & 0.37 & 0.48 & 15.4 & 10.6 & 0.61 & 0.45 \\
N & 4976 &. & 4059 &. & 4162 &. & 4365 &. \\
\hline \hline
\end{tabular}

Notes. This table reports breakdowns by firm size. There are 103 firms in this sample with unknown employment as of January. All measures are coded according to the notes in Table 1. 
Table 3: Summary Measures by Industry

\begin{tabular}{|c|c|c|c|c|c|c|c|c|}
\hline & \multicolumn{2}{|c|}{$\begin{array}{c}\text { Currently } \\
\text { Closed }\end{array}$} & \multicolumn{2}{|c|}{$\begin{array}{l}\text { Exp Closed } \\
\text { December }\end{array}$} & \multicolumn{2}{|c|}{$\begin{array}{c}\text { Weeks COVID } \\
\text { Will Last }\end{array}$} & \multicolumn{2}{|c|}{$\begin{array}{c}\text { Current v Jan } \\
\text { Employment }\end{array}$} \\
\hline & Mean & $\mathrm{SD}$ & Mean & $\mathrm{SD}$ & Mean & $\mathrm{SD}$ & Mean & $\mathrm{SD}$ \\
\hline \multicolumn{9}{|c|}{ Panel A: Raw Data } \\
\hline All Retailers, except Grocery & 0.53 & 0.50 & 0.45 & 0.50 & 14.1 & 9.5 & 0.49 & 0.42 \\
\hline Arts and entertainment & 0.70 & 0.46 & 0.42 & 0.49 & 17.5 & 11.3 & 0.40 & 0.46 \\
\hline Banking/finance & 0.19 & 0.39 & 0.25 & 0.43 & 16.1 & 10.9 & 0.81 & 0.33 \\
\hline Construction & 0.32 & 0.47 & 0.38 & 0.49 & 14.3 & 10.3 & 0.66 & 0.40 \\
\hline Health care & 0.45 & 0.50 & 0.29 & 0.45 & 15.1 & 10.4 & 0.69 & 0.37 \\
\hline Other & 0.39 & 0.49 & 0.35 & 0.48 & 16.6 & 11.2 & 0.70 & 0.41 \\
\hline Personal Services & 0.86 & 0.34 & 0.39 & 0.49 & 11.8 & 8.3 & 0.35 & 0.40 \\
\hline Professional Services & 0.21 & 0.41 & 0.29 & 0.45 & 15.7 & 10.6 & 0.80 & 0.41 \\
\hline Real Estate & 0.37 & 0.48 & 0.30 & 0.46 & 15.8 & 11.4 & 0.70 & 0.41 \\
\hline Restaurant/Bar/Catering & 0.56 & 0.50 & 0.52 & 0.50 & 13.1 & 8.7 & 0.24 & 0.37 \\
\hline Tourism/Lodging & 0.61 & 0.49 & 0.45 & 0.50 & 16.2 & 10.0 & 0.30 & 0.35 \\
\hline Total & 0.45 & 0.50 & 0.37 & 0.48 & 15.5 & 10.6 & 0.58 & 0.44 \\
\hline $\mathrm{N}$ & 4413 & . & 3953 & . & 4000 & . & 3935 & . \\
\hline
\end{tabular}

Panel B: Re-Weighted to Census by Size and Region

\begin{tabular}{lcccccccc} 
All Retailers, except Grocery & 0.53 & 0.50 & 0.44 & 0.50 & 14.3 & 9.8 & 0.51 & 0.42 \\
Arts and entertainment & 0.70 & 0.46 & 0.41 & 0.49 & 17.1 & 11.4 & 0.43 & 0.47 \\
Banking/finance & 0.20 & 0.40 & 0.25 & 0.43 & 16.3 & 11.1 & 0.84 & 0.30 \\
Construction & 0.33 & 0.47 & 0.38 & 0.49 & 14.4 & 10.3 & 0.71 & 0.38 \\
Health care & 0.43 & 0.50 & 0.28 & 0.45 & 14.5 & 10.1 & 0.72 & 0.35 \\
Other & 0.39 & 0.49 & 0.34 & 0.47 & 16.4 & 11.2 & 0.74 & 0.38 \\
Personal Services & 0.86 & 0.34 & 0.39 & 0.49 & 11.9 & 8.4 & 0.37 & 0.40 \\
Professional Services & 0.21 & 0.41 & 0.30 & 0.46 & 15.6 & 10.7 & 0.80 & 0.41 \\
Real Estate & 0.37 & 0.48 & 0.31 & 0.47 & 15.6 & 11.0 & 0.74 & 0.39 \\
Restaurant/Bar/Catering & 0.58 & 0.49 & 0.49 & 0.50 & 13.4 & 9.0 & 0.23 & 0.36 \\
Tourism/Lodging & 0.60 & 0.49 & 0.43 & 0.50 & 16.1 & 9.9 & 0.31 & 0.35 \\
Total & 0.45 & 0.50 & 0.36 & 0.48 & 15.4 & 10.6 & 0.61 & 0.43 \\
$\mathrm{~N}$ & 4326 &. & 3877 &. & 3921 &. & 3935 &. \\
\hline \hline
\end{tabular}

Notes. This table reports breakdowns by industry. Panel A contains raw data and Panel B contains data re-weighted to match the Census share of firms by size and region bucket. Missing industry information explains differences in observations between Panel A and prior analysis. Differences in observations between Panels A and B arise from firms with unknown January employment or region. All measures are coded according to the notes in Table 1. 
Table 4: Breakdown of Issues Affecting Businesses

\begin{tabular}{|c|c|c|c|c|c|}
\hline & N (Total) & N (Answering) & Supply Chain & "Employee Health & Demand/Orders \\
\hline \multicolumn{6}{|c|}{ Panel A: Raw Data } \\
\hline Currently open & 2,759 & 2,196 & 30.2 & 49.8 & 66.2 \\
\hline Temp. closed & 2,116 & 1,774 & 35.5 & 59.7 & 83.4 \\
\hline Perm. closed & 100 & 85 & 37.9 & 60.8 & 86.1 \\
\hline Total & 4,975 & 4,055 & 34.6 & 56.8 & 78.6 \\
\hline \multicolumn{6}{|c|}{ Panel B: Re-Weighted to Census by Size and Region } \\
\hline Currently open & 2,698 & 2,149 & 30.4 & 50.4 & 65.9 \\
\hline Temp. closed & 2,080 & 1,744 & 35.7 & 60.2 & 83.7 \\
\hline Perm. closed & 94 & 80 & 39.2 & 63.6 & 85.8 \\
\hline Total & 4,872 & 3,973 & 35.1 & 58.1 & 78.5 \\
\hline
\end{tabular}

Notes. This table reports respondents' reactions to the importance of issues affecting their business, broken down by the status of the business at the time of taking the survey. 
Table 5: Reported Likelihood of Remaining Open by Industry and Hypothetical Crisis DURATION

\begin{tabular}{|c|c|c|c|c|}
\hline Industry & $\overline{\mathrm{N}}$ & 1 Month & 4 Months & 6 Montl \\
\hline \multicolumn{5}{|c|}{ Panel A: Raw Data } \\
\hline All Retailers, except Grocery & 490 & 0.68 & 0.35 & 0.34 \\
\hline Arts and entertainment & 281 & 0.66 & 0.45 & 0.35 \\
\hline Banking/finance & 148 & 0.78 & 0.61 & 0.60 \\
\hline Construction & 383 & 0.72 & 0.43 & 0.45 \\
\hline Health care & 395 & 0.78 & 0.47 & 0.35 \\
\hline Other & 1,384 & 0.76 & 0.48 & 0.38 \\
\hline Personal Services & 168 & 0.57 & 0.40 & 0.19 \\
\hline Professional Services & 201 & 0.79 & 0.64 & 0.55 \\
\hline Real Estate & 93 & 0.74 & 0.57 & 0.58 \\
\hline Restaurant/Bar/Catering & 163 & 0.74 & 0.29 & 0.19 \\
\hline Tourism/Lodging & 145 & 0.63 & 0.50 & 0.25 \\
\hline Total & 3,851 & 0.72 & 0.47 & 0.39 \\
\hline
\end{tabular}

Panel B: Re-Weighted to Census by Size and Region

\begin{tabular}{lcccc} 
All Retailers, except Grocery & 485 & 0.69 & 0.35 & 0.34 \\
Arts and entertainment & 271 & 0.66 & 0.45 & 0.36 \\
Banking/finance & 144 & 0.78 & 0.64 & 0.62 \\
Construction & 372 & 0.72 & 0.42 & 0.46 \\
Health care & 386 & 0.77 & 0.47 & 0.37 \\
Other & 1,361 & 0.76 & 0.48 & 0.39 \\
Personal Services & 167 & 0.56 & 0.37 & 0.19 \\
Professional Services & 197 & 0.79 & 0.62 & 0.56 \\
Real Estate & 93 & 0.72 & 0.55 & 0.59 \\
Restaurant/Bar/Catering & 160 & 0.75 & 0.35 & 0.19 \\
Tourism/Lodging & 143 & 0.65 & 0.52 & 0.23 \\
Total & 3,779 & 0.71 & 0.47 & 0.39 \\
\hline \hline
\end{tabular}

Notes. This table reports results of expectations about remaining open in December under different hypothetical durations of the COVID crisis. This question was asked at the end of the survey, after policy questions were conducted. The randomization is between subject. 
Table 6: Extensive Margin Separations Arising from Firm Closures Over Different Hypothetical Crisis Duration (All Numbers in Millions)

\begin{tabular}{lccccc}
\hline $\begin{array}{l}\text { January } \\
\text { Employees }\end{array}$ & $\begin{array}{c}\text { 2017 Census } \\
\text { Firms }\end{array}$ & $\begin{array}{c}\text { 2017 Census } \\
\text { Employees }\end{array}$ & $\begin{array}{c}\text { End-of-2020 Separations if Crisis Lasts: } \\
\text { 1 Month }\end{array}$ & 4 Months & 6 Months \\
\hline \hline Under 5 & 3.7 & 5.9 & 1.6 & 3.1 & 3.6 \\
$6-24$ & 1.8 & 18.1 & 4.8 & 10.5 & 12.1 \\
$25-49$ & 0.3 & 9.5 & 1.6 & 4.4 & 6.9 \\
$50+$ & 0.3 & 26.8 & 5.8 & 14.6 & 12.5 \\
Total & 6.1 & 60.4 & 13.7 & 32.7 & 35.1 \\
\hline \hline
\end{tabular}

Notes. This table reports results of end-of-2020 employment separations based on extensive margin business closures using the between-subjects survey design that asked about the ability to remain open under different crisis durations in Table 5. We take the fraction of businesses closing by December 2020 as the complement of the numbers in table 5 and then multiply by the number of 2017 employees (in millions) from the Census, yielding the implied level of employment separations in each cell. 
Table A1: Census Industry versus Survey Industry Breakdown

\begin{tabular}{lcc}
\hline \hline Industry & Census Percentage & Survey Percentage \\
\hline Agriculture, Forestry, Fishing and Hunting & 0.4 & 1.3 \\
Mining, Quarrying, and Oil and Gas Extraction & 0.3 & 0.0 \\
Utilities & 0.1 & 0.0 \\
Construction & 11.7 & 13.2 \\
Manufacturing & 4.1 & 3.1 \\
Wholesale and Retail Trade & 15.7 & 18.5 \\
Transportation and Warehousing & 3.1 & 2.7 \\
Information & 1.3 & 2.8 \\
Finance and Insurance & 4.0 & 5.2 \\
Real Estate and Rental and Leasing & 5.2 & 4.2 \\
Professional, Scientific, and Technical Services & 13.5 & 7.7 \\
Management of Companies and Enterprises & 0.3 & 0.0 \\
Administrative and Support and Waste Remediation Svcs & 5.8 & 1.4 \\
Educational Services & 1.5 & 2.3 \\
Health Care and Social Assistance & 10.9 & 13.3 \\
Arts, Entertainment, and Recreation & 2.2 & 9.0 \\
Accommodation and Food Services & 9.0 & 8.3 \\
Other Services (except Public Administration) & 11.6 & 7.1 \\
\hline \hline
\end{tabular}

Notes. This table reports results of Census and Survey shares by industry for firms with fewer than 500 employees. Survey response shares are conditional on being able to classify industries, with unavailable or "Other" industry classifications omitted from the denominator. We combine wholesale and retail trade due to the difficulty in separating these out in the survey. 